Journal for ImmunoTherapy of Cancer

\title{
First immunotherapeutic CAR-T cells against the immune checkpoint protein HLA-G
}

\author{
François Anna, ${ }^{1,2}$ Elodie Bole-Richard, ${ }^{3,4,5}$ Joel LeMaoult, ${ }^{6,7}$ Marie Escande, ${ }^{1}$ \\ Martin Lecomte, ${ }^{1}$ Jean-Marie Certoux, ${ }^{3,4,5}$ Philippe Souque, ${ }^{2}$ \\ Francine Garnache, ${ }^{3,4,5}$ Olivier Adotevi (D) , , ", ${ }^{3}$ Pierre Langlade-Demoyen, ${ }^{1}$ \\ Maria Loustau, ${ }^{1}$ Julien Caumartin (1) ${ }^{1}$
}

To cite: Anna F, Bole-Richard E, LeMaoult J, et al. First immunotherapeutic CAR-T cells against the immune checkpoint protein HLA-G. Journal for ImmunoTherapy of Cancer 2021;9:e001998. doi:10.1136/ jitc-2020-001998

- Additional material is published online only. To view, please visit the journal online (http://dx.doi.org/10.1136/jitc2020-001998).

Accepted 15 February 2021

Check for updates

(c) Author(s) (or their employer(s)) 2021. Re-use permitted under CC BY-NC. No commercial re-use. See rights and permissions. Published by BMJ.

For numbered affiliations see end of article.

Correspondence to

Dr Julien Caumartin;

julien.caumartin@invectys.com

\section{ABSTRACT}

Background CAR-T cells immunotherapy is a breakthrough in the treatment of hematological malignancies such as acute lymphoblastic leukemia (ALL) and B-cell malignancies. However, CAR-T therapies face major hurdles such as the lack of tumor-specific antigen (TSA), and immunosuppressive tumor microenvironment sometimes caused by the tumorous expression of immune checkpoints (ICPs) such as HLA-G. Indeed, HLA-G is remarkable because it is both a potent ICP and a TSA. HLA-G tumor expression causes immune escape by impairing innate and adaptive immune responses and by inducing a suppressive microenvironment. Yet, to date, no immunotherapy targets it.

Methods We have developed two anti-HLA-G thirdgeneration CARs based on new anti-HLA-G monoclonal antibodies.

Results Anti-HLA-G CAR-T cells were specific for immunosuppressive HLA-G isoforms. HLA-G-activated CAR-T cells polarized toward T helper 1 , and became cytotoxic against $\mathrm{HLA}_{-} \mathrm{G}^{+}$tumor cells. In vivo, antiHLA-G CAR-T cells were able to control and eliminate $\mathrm{HLA}-\mathrm{G}^{+}$tumor cells. The interaction of tumor-HLA-G with interleukin (IL)T2-expressing T cells is known to result in effector T cell functional inhibition, but anti-HLA-G CAR-T cells were insensitive to this inhibition and still exerted their function even when expressing ILT2. Lastly, we show that anti-HLA-G CAR-T cells differentiated into long-term memory effector cells, and seemed not to lose function even after repeated stimulation by HLA-G-expressing tumor cells.

Conclusion We report for the first time that HLA-G, which is both a TSA and an ICP, constitutes a valid target for CAR-T cell therapy to specifically target and eliminate both tumor cells and $\mathrm{HLA}-\mathrm{G}^{+}$suppressive cells.

\section{INTRODUCTION}

CAR-T cell is a breakthrough immunotherapy that redirects $\mathrm{T}$ cell function against specific tumor antigens. ${ }^{12}$ Exceptional results were obtained in the treatment of B-cell malignancies, and recently approved by the Food and Drug Administration and the European Medicines Agency for acute lymphoblastic leukemia and diffuse large B-cell lymphoma treatments in adults. ${ }^{34}$ The main hurdles for the application to other tumors are the identification of proper tumorspecific antigens (TSA), ${ }^{5}$ and the existence of immune-suppressive tumor microenvironment (TME), particularly in solid tumors. ${ }^{6} 7$ Immune-suppressive TME is caused in part by tumor-driven immune-suppressive populations such as myeloid-derived suppressor cells, tumor-associated macrophages or neutrophils that secrete immune-suppressive cytokines, ${ }^{8}$ and by expression of immune checkpoints (ICPs). The negative impact of ICP on CAR-T cell therapy efficiency was demonstrated for programmed cell death protein 1 (PD-1)/programmed death-ligand 1 (PD-L1). ${ }^{910}$ Thus, in most CAR-T cell developments, the challenges are (i) to target a specific tumor antigen (to avoid 'on-target off-tumor' effect ${ }^{11}$ and (ii) to bypass inhibition by ICPs. The association of CAR-T cells with anti-PD-1 has shown benefits in clinical trials, by lifting PD-1-driven inhibition of CAR-T cells. ${ }^{12}$ However, this strategy increases the risk of a general immune system dysregulation, and also increases the already heavy burden on patients. ${ }^{13}$

HLA-G is an ICP molecule first shown to be expressed on fetal trophoblasts that invade the immune-aggressive maternal decidua. ${ }^{14-17}$ In adults, HLA-G expression is strictly restricted to few tissues, ${ }^{18-24}$ but in the context of cancer, it is often neo-expressed by tumor cells (for review, including per-cancertype HLA-G expression data, see Loustau et $a l^{25}$ Carosella et $a l^{26}$ and Lin and $\mathrm{Yan}^{27}$ ). The association of a physiological absence of expression and a common expression by tumor cells makes of HLA-G a particularly tumor-specific target. ${ }^{28} 29$ In this regard, HLA-G differs from other checkpoints that are physiologically expressed in adult tissues 
and therefore expressed by tumor cells 'in addition to' other tissues.

The primary function of HLA-G is to protect histologically incompatible fetal tissues against destruction by the maternal immune system. It does so by broadly inhibiting all actors of an immune response (B, T and natural killer (NK) cells, monocytes/dendritic cells, neutrophils) mainly through two inhibitory receptors: interleukin ILT2 and ILT4. ${ }^{26}$ HLA-G also induces a strong immunesuppressive microenvironment through the induction of suppressive NK cells, ${ }^{30} \mathrm{~T}$ cells ${ }^{31}$ and antigen-presenting cells. ${ }^{32}$ When expressed by tumor cells, HLA-G exerts the same functions and efficiently protects them against destruction. Consequently, HLA-G neo-expression in cancer was always associated with worse prognosis, poor clinical outcome of patients with cancer and with worse overall survival. ${ }^{25}$ Finally, the demonstration that HLA-G acts as an immune escape mechanism for tumors was formally made in animal models. ${ }^{33} 34$

Despite these characteristics, HLA-G was not targeted during the first wave of immune therapy development, probably because of its structural complexity and the lack of a murine homolog. Nevertheless, we reasoned that anti-HLA-G CAR-T cell innovative immune therapeutic approach would be highly relevant, HLA-G being a highly TSA, and an ICP, that is, a tumor-specific ICP. In this study, we generated several anti-HLA-G CARs using the scFv of high-affinity anti-HLA-G monoclonal antibodies. These were generated to specifically recognize the HLA-G isoforms interacting with the ILT2 and ILT4 receptors. We show that in vitro, anti-HLA-G CAR-T cells were specifically cytotoxic against HLA-G-expressing targets, insensitive to inhibition through the HLA-G:ILT2 pathway and that they acquire a $\mathrm{T}$ effector memory (TEM) phenotype on multiple antigenic stimulations by HLA-G. In vivo, anti-HLA-G CAR-T cells eradicated implanted HLA-Gexpressing tumor cells. This is the first demonstration that anti-HLA-G CAR-T therapy may be a viable and flexible clinical approach to target many tumor types that may not express known TSA.

\section{MATERIALS AND METHODS}

\section{Construction of CARs and T-cell culture transduction}

Six anti-HLA-G CAR constructs were generated with the scFv of LFTT1 and 15E7 monoclonal antibodies (mAbs) developed and cloned into a third-generation lentiviral plasmid backbone under the regulation of a human EF1 $\alpha$ promoter. ${ }^{35}$ CAR-T cells and activated non-transduced (NT) T cells were generated as previously decribed. ${ }^{35}$

\section{Vector production}

HIV-1-derived vector particles were produced by transient calcium phosphate co-transfection of HEK $293 \mathrm{~T}$ cells (American Type Culture Collection (ATCC)) with the vector plasmid pTRIP encoding the vector RNA, an envelope expression plasmid encoding the glycoprotein from VSV serotype Indiana, and the p8.74 encapsidation plasmid for the production of integrative lentiviral vector particles. Vector gene transfer capacity was determined by quantitative PCR after transduction of $293 \mathrm{~T}$ cells as previously described and was expressed as transduction unit/mL of vector.

\section{Cell lines}

In this study, we used the JEG-3 choriocarcinoma cell line that endogenously expresses HLA-G (ATCC), the HLAclass I-negative erythroblastoid cell line K562 (ATCC) and the 293 T cell line (ATCC) transfected with HLA-G5wt or mutated HLA-G5 isoforms. As shown in online supplemental figure 1, JEG-3 cells express only HLA-G1/ $\beta 2$ massociated isoform whereas K562-HLA-G1 cells express both HLA-G1/ $\beta 2 \mathrm{~m}$-associated and HLA-G1/ $\beta 2 \mathrm{~m}$-free isoforms.

\section{$T$ cell isolation and activation}

The peripheral blood mononuclear cells (PBMCs) from healthy donors were obtained by Ficoll isolation. $\mathrm{T}$ cells were sorted by column purification (Miltenyi), activated with $\mathrm{CD} 3 / \mathrm{CD} 28$ microbeads (Miltenyi) and cultivated 48 hours at $37^{\circ} \mathrm{C}$ in a $5 \% \mathrm{CO}_{2}$ incubator in RPMI 1640 (Gibco) supplemented with $10 \%$ fetal calf serum, $1 \%$ penicillin-streptomycin (Gibco), $50 \mu \mathrm{M}$ betamercaptoethanol (Gibco), non-essential amino acid, 10 mM HEPES (Gibco), $1 \mathrm{mM}$ sodium pyruvate (Gibco). Transduced cells were used 8 days after transduction.

\section{Activation profile and degranulation assay}

The day prior to the assay, $3 \times 10^{4}$ JEG-3 cells were labeled with $1 \mu \mathrm{M}$ of CFSE (CellTrace, Thermo Fisher) and seeded in flat-bottom 96-well microplates. On the day of the assay, CAR-T cells were added at various E:T ratios to either the plated CFSE-labeled JEG-3 cells or $3 \times 10^{4}$ CFSElabeled K562/K562-HLA-G1 cells. After 24 hours incubation, medium was collected and cells recovered, washed and labeled with antibodies against CD4 (clone RPA-T4, Biolegend), CD8 (clone RPA-T8, Biolegend), CD19 (HIB19, Biolegend), CD25 (clone M-A251, BD Bioscience), CD69 (clone FN-50, BD Bioscience), PD-1 (EH12.2h7, Biolegend) and a viability dye (Invitrogen). For degranulation assays, co-cultures were set-up at an E:T ratio of 10:1. Anti-CD107a (clone eBioH4A3, Biolegend) was added at the start of the experiment, GolgiStop (BD Bioscience) was added after 1 hour. Five hours after the beginning of the assay, cells were collected and labeled with antibodies directed against CD4, CD8, CD19 and a viability dye. Acquisition was performed with a fluorescence-activated cell sorting (FACS) Attune (Thermo Fisher), and results were analyzed with FlowJo software.

\section{Cytokine secretion profile}

CAR-T cells $15 \mathrm{E} 7^{\mathrm{CH} 2-\mathrm{CH} 3}\left(2 \times 10^{5}\right)$ and LFTT1 ${ }^{\mathrm{CH} 2-\mathrm{CH} 3}$ were seeded with $2 \times 10^{5}$ K562-HLA-G1 in a U-bottom 96-well plate and centrifuged at $100 \mathrm{~g}$ during $1 \mathrm{~min}$. Cells were incubated 1 hour at $37^{\circ} \mathrm{C}$ in a $5 \% \mathrm{CO}_{2}$ incubator then brefeldin A ( $5 \mu \mathrm{g} / \mathrm{mL}, \mathrm{BD}$ Biosciences) was added. Cell were incubated 18 hours longer at $37^{\circ} \mathrm{C}$ in a $5 \% \mathrm{CO}_{2}$ 
incubator. For FACS analysis, cells were labeled with anti-CD8 (clone RPA-T8, Biolegend), CD19 (HIB-19, Biolegend), interferon (IFN) $\gamma$ (clone 4S.B3, Biolegend), tumor necrosis factor (TNF) $\alpha$ (clone MAb11, Biolegend), IL-2 (MQ1-17H12, Biolegend) and a viability dye.

\section{Phenotype variation after multiple stimulations}

Co-cultures were set up with CAR-T cells and K562HLA-G1 cells at an E:T ratio of 10:1 with no IL-2. Twentyfour hours after stimulation, $50 \mu \mathrm{L}$ of medium were taken, stored for cytokine secretion analysis and replaced by complete RPMI. Seventy-two hours after stimulation, half of the medium was changed with complete RPMI supplemented with $50 \mathrm{U} / \mathrm{mL}$ of IL-2. Cells were maintained at $10^{6} / \mathrm{mL}$. Twelve days after stimulation, some cells were used for flow cytometry analysis, whereas the rest was used for a new round of stimulation. A total of three consecutive stimulations were performed. For flow cytometry analysis, cells were labeled with antibodies directed against CD4 (clone RPA-T4, Biolegend), CD8 (clone RPA-T8, Biolegend), CD19 (HIB-19, Biolegend), CD62L (clone DREG-56, BD Bioscience) and CD45RA (clone HI-100, Invitrogen). In these experiments, the phenotype of CAR-T cells and activated NT autologous controls was also established 24 hours prior to the assay. At the end of the experiment, all recovered medium was analyzed for IFN $\gamma$, TNF $\alpha$ and IL-2 secretion using a cytometric bead array (CBA) kit (BD Biosciences).

\section{In vivo models}

NOD/SCID/IL-2R $\gamma c-d e f i c i e n t$ (NSG) mice (6-8 weeks of age) were purchased from Charles River Laboratories (L'Arbresle, France) and housed in filter-top cages with freely available food and sterile water (Plexx), at the UMR1098 Animal facility (agreement \#C25-056-7). At day -1 , a 2.5 Gy single-dose total body irradiation was applied. Twenty-four hours later, mice were inoculated intravenously with $10^{6}$ luciferase-expressing K562-HLA-G1 cells. On day $3,10^{7}$ CAR-T cells were injected into the tail vein. Engraftment was monitored weekly by bioluminescence measurements: mice received $3 \mathrm{mg}$ of luciferin (VivoGlo Luciferin, \#P1043, Promega, Fitchburg, Wisconsin, USA) intraperitoneally within 10 min of imaging (IVIS Lumina Series III, Perkin Elmer, Waltham, Massachusetts, USA). Detailed methods are provided in online supplemental methods.

\section{RESULTS \\ Anti-HLA-G CAR-T cells targeting immunosuppressive HLA-G isoforms}

HLA-G is a complex protein. First, its splicing pattern yields at least four membrane-bound isoforms that can be shed, and three soluble ones, ${ }^{36}$ and new splicing isoforms were recently described.$^{37}$ In addition, HLA-G heavy chain may, or may not be associated with $\beta 2 \mathrm{~m}$, depending on the isoform and possibly on the environment. In sharp contrast with this diversity, little is known of HLA-G isoforms other than $\beta 2 \mathrm{~m}$-associated HLA-G1/ HLA-G5 ( $\alpha 1-\alpha 2-\alpha 3$ domains) and $\beta 2 \mathrm{~m}$-free HLA-G2/ HLA-G6 ( $\alpha 1-\alpha 3$ domains) for which immune-modulatory function has been well described in vitro. ${ }^{38} 39$ HLA-G1/ $\beta 2 \mathrm{~m}$-associated isoform is mainly expressed in several tumor contexts, whereas HLA-G/ $/ \beta 2 \mathrm{~m}$-free molecules were detected in melanoma. ${ }^{28}$

Our goal was to specifically target HLA-G1/ $\beta 2 \mathrm{~m}$ associated and HLA-G1/ $\beta 2 \mathrm{~m}$-free immunosuppressive isoforms whose inhibitory functions depend on the interaction with ILT2 and/or ILT4. For this purpose, we generated new antibodies: the LFTT1 monoclonal antibody is specific for the HLA-G- $\alpha 1$ domain of $\beta 2 \mathrm{~m}$ associated HLA-G1/HLA-G5 isoforms, whereas the 15E7 monoclonal antibody binds to $\beta 2 \mathrm{~m}$-free HLA-G isoforms and is specific for the unique F-D-Y amino acid loop in HLA-G- $\alpha 3$ domain (figure 1A). Information on these antibodies is provided in online supplemental figure 1.

Based on LFTT1 and 15E7 scFv, we generated two thirdgeneration anti-HLA-G CAR sets: CAR-LFTT1 and CAR15E7. The CAR-LFTT1 set targets the HLA-G- $\alpha 1$ domain, distal from the membrane, whereas the CAR-15E7 set targets HLA-G-alpha3, proximal to the membrane. Because accessibility to the epitopes by the CAR protein was an issue, each set comprises three CAR constructs, with different hinges. Hinges were: classical IgG4 (CARLFTT1 and CAR-15E7), IgG4+CH3 (CAR-LFTT1 ${ }^{\mathrm{CH} 3}$ and CAR-15E $7^{\mathrm{CH} 3}$ ) and IgG4+CH2-CH3 (CAR-LFTT1 ${ }^{\mathrm{CH} 2-\mathrm{CH} 3}$ and $\mathrm{CAR}-15 \mathrm{E} 7^{{ }^{\mathrm{CH} 2-\mathrm{CH} 3} \text { ) }}$ (figure $\left.1 \mathrm{~B}\right) .^{40} \mathrm{CAR}$ constructs also contained human-derived CD28 transmembrane domain, CD28 and 4-1BB co-stimulation domains to improve CAR-T cell cytotoxic function and persistence, ${ }^{41}$ and human $\mathrm{CD} 3 \zeta$ chain. Anti-HLA-G CAR constructs were introduced in an HIV-1-derived lentiviral vector (figure 1C) co-expressing a truncated CD19 protein, reporter for CAR cell-surface expression on transduced cells (figure 1D). ${ }^{35}$

In all subsequent experiments, CAR expression was assessed using CD19 reporter (trCD19) expression levels as reported. ${ }^{35}$

\section{Anti-HLA-G CAR-T are specific and efficient effector cells}

CAR-LFTT1 and CAR-15E7 function was expected to follow staining patterns of LFTT1 and 15E7 mAbs: control K562 cells are not stained by 15E7 or LFTT1 mAbs, whereas K562-HLA-G1 cells are stained by both, and JEG-3 cells are only stained by LFTT1 (figure 2A).

All CAR-T cells were tested against HLA-G-expressing K562-HLA-G1 and JEG-3 targets, using K562 cells as HLAG-negative controls, and autologous activated T cells as non-transduced controls. At the end of the experiments, we investigated the upregulation of activation-associated markers (CD25, CD69, PD-1), degranulation (CD107a upregulation) and tumor cell lysis.

Upregulation of CD25 vs CD69 is shown in figure 2B for a representative experiment and the classical hinge: on stimulation by HLA-G-positive cells, anti-HLA-G CAR-T cells expressed both CD25 and CD69 markers at their 
A

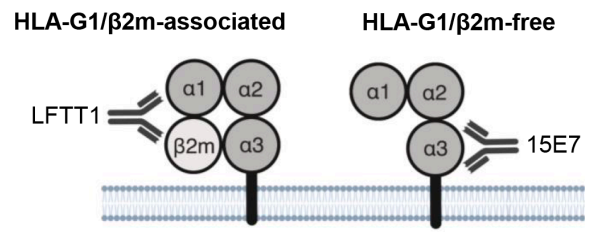

B

$$
\begin{aligned}
& \text { Classical lgG4 Hinge } \\
& \text { CAR-LFT1 Hinge } \\
& \text { CAR-15E7 Hinge }
\end{aligned}
$$
IgG4 Hinge + $\mathrm{CH} 3$ CAR-LFTT1 CH

IgG4 Hinge + $\mathrm{CH} 2-\mathrm{CH} 3$ CAR-LFTT1 CH2-CH3

CD19 Reporter CAR-15E7 ${ }^{\mathrm{CH} 3}$ CAR-15E7 $\mathrm{CH}^{2} \mathrm{CH} 3$ trCD19

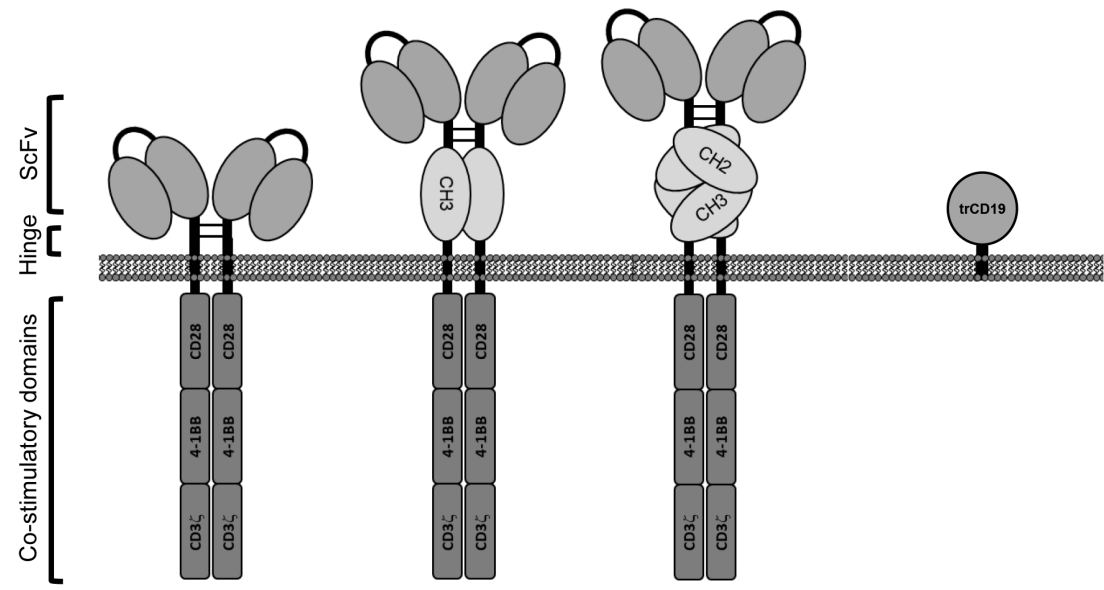

C

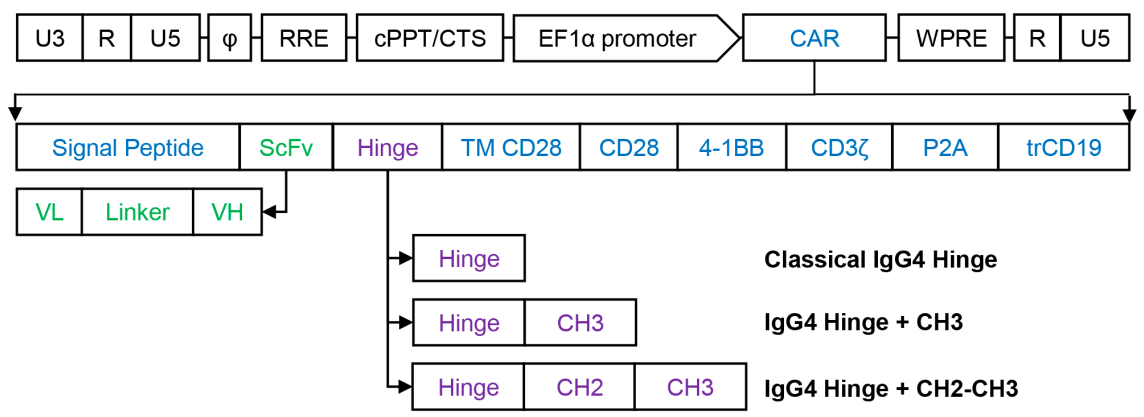

D

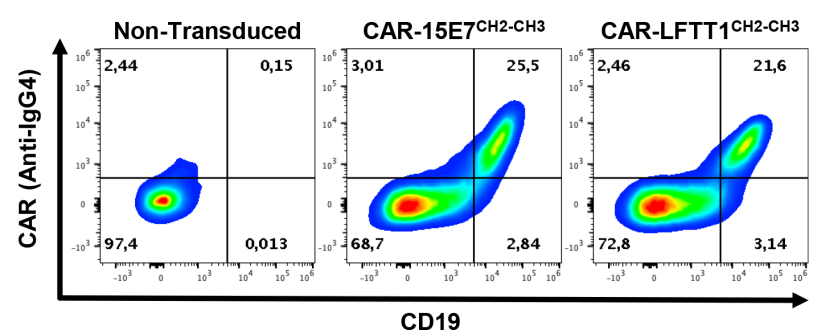

Figure 1 Anti-HLA-G CAR design and expression vector. (A) Schematic representation of anti-HLA-G monoclonal antibodies specificities: LFTT1 monoclonal antibody (mAb) is specific for HLA-G1//2m-associated isoform and $15 \mathrm{E} 7 \mathrm{mAb}$ is specific for HLA-G1/ß2m-free isoform. (B) Schematic representation of the third-generation anti-HLA-G CAR protein and lentiviral vector backbones used to transduce human $\mathrm{CD}^{+} \mathrm{T}$ cells. $(\mathrm{C})$ Lentiviral constructs details; SP: signal peptide from mouse Igк. scFv: single chain fragment from either LFTT1 (CAR-LFTT1) or 15E7 (CAR-15E7). Hinges: classical IgG4 hinge, IgG4 hinge $+\mathrm{CH} 3$ domain of human IgG4 and IgG4 hinge+CH2-CH3 domain of human IgG4. TM CD28: transmembrane domain of

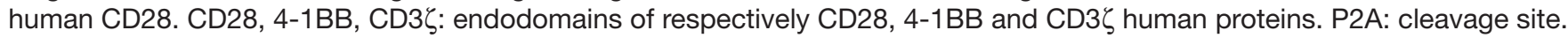
trCD19: truncated CD19. U3, R, U5: HIV-1 LTR regions. $\Phi$ : encapsidation signal. RRE, Rev Response Element. EF1 $\alpha$, full length elongation factor-1 $\alpha$ promoter. WPRE, Woodchuck Post-transcriptionnal Response element mutated for HBx ATG codon start. (D) Validation of transduction and co-expression of CAR using the CAR ${ }^{\mathrm{CH} 2-\mathrm{CH} 3}$ construct proteins and trCD19 reporter for both CAR-LFTT1 and CAR-15E7 T cells from primary human T cells. Transduced T cells were labeled with CD19 and IgG4 antibodies and analyzed by flow cytometry.

surface, following the specificity pattern of LFTT1 and $15 \mathrm{E} 7 \mathrm{mAbs}$. As shown in figure $2 \mathrm{C}$ for three individual experiments, upregulation of CD25, CD69 and PD-1 occurred in 30\%-50\% of CAR-expressing CD8 ${ }^{+} \mathrm{T}$ cells (trCD $19^{+}$fraction) on incubation with cells expressing the HLA-G structures targeted by LFTT1 or 15E7 mAbs. 
A

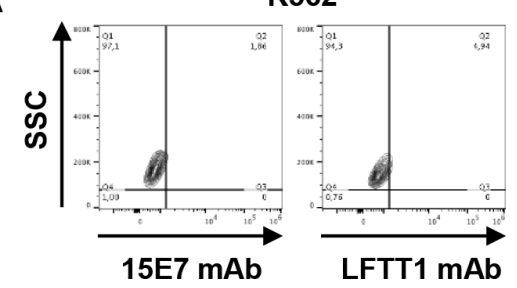

K562-HLA-G1

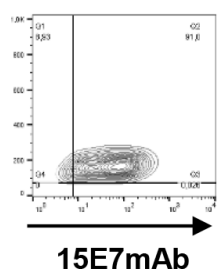

JEG-3

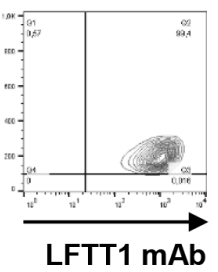

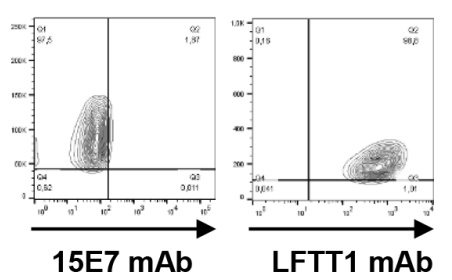

B

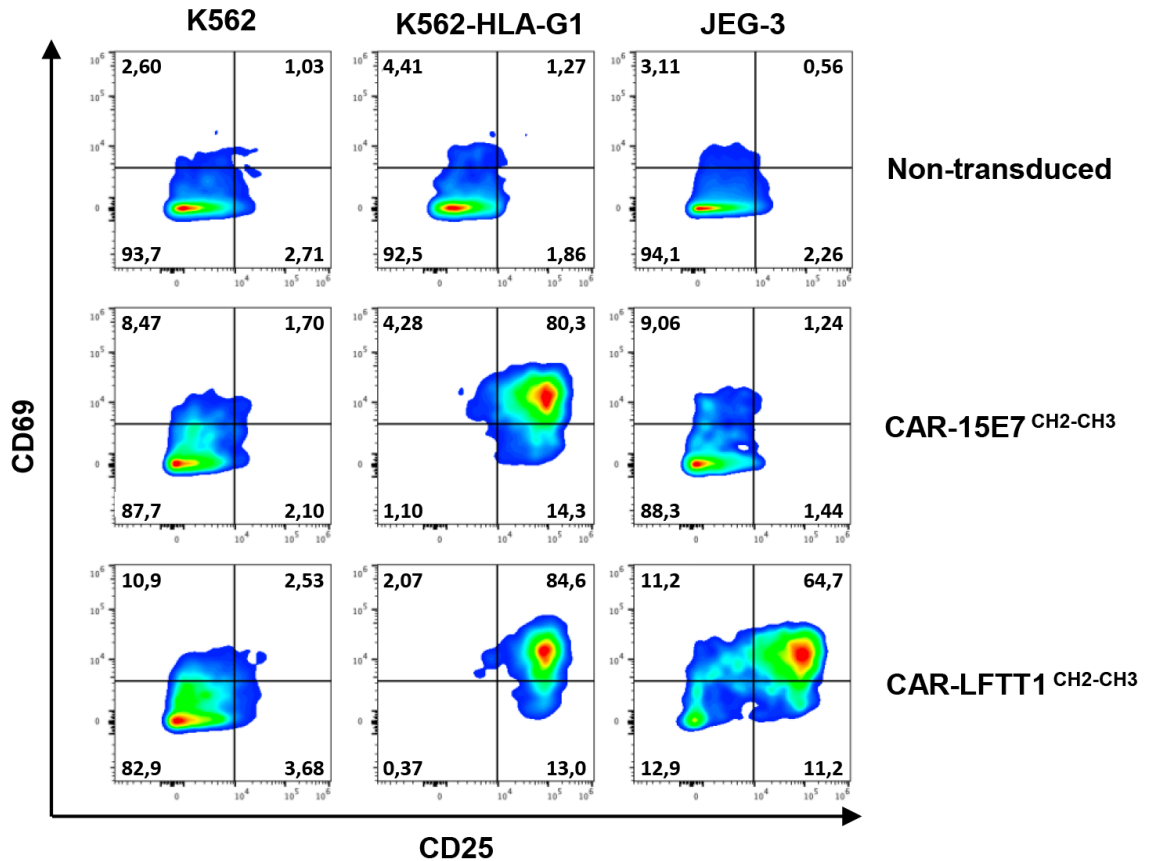

C
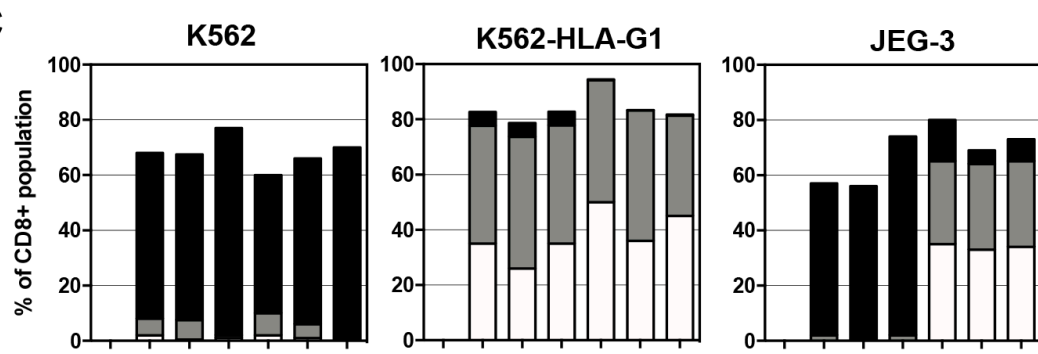

Naives

$\square \mathrm{CD} 69+\mathrm{CD} 25+$

$\square \mathrm{CD} 69+\mathrm{CD} 25+\mathrm{PD} 1+$

\section{CAR $^{\text {pos }}$}
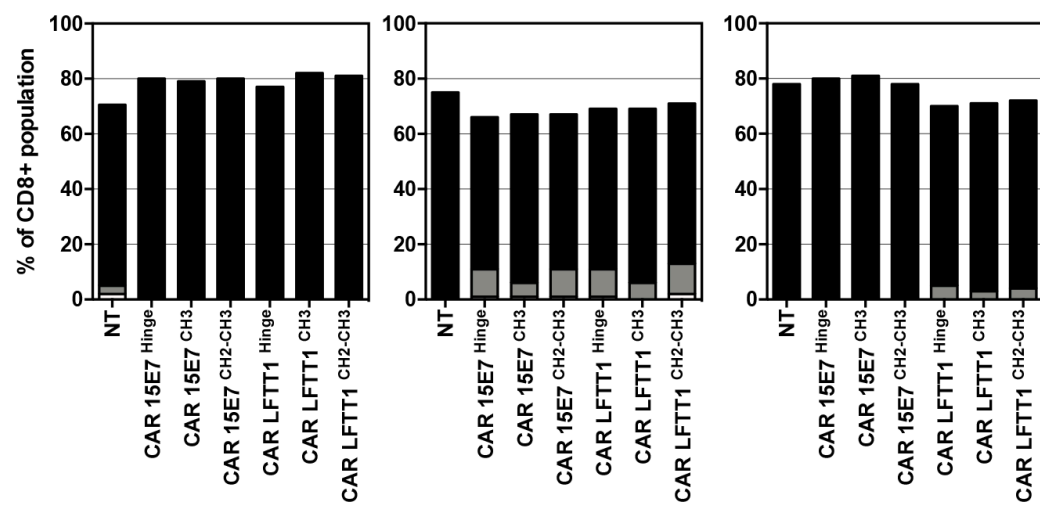

Naives

$\square \mathrm{CD} 69+\mathrm{CD} 25+$

$\square \mathrm{CD} 69+\mathrm{CD} 25+\mathrm{PD} 1+$

\section{CAR $^{\text {neg }}$}

Figure 2 Anti-HLA-G CAR-T cells are specific and activated by different HLA-G isoforms. (A) Anti-HLA-G monoclonal antibodies specificity against HLA-G ${ }^{-/}$cell lines. Representative dot plot of K562, K562-HLA-G1 and JEG-3 tumor cell lines labeling with the anti-HLA-G 15E7 and LFTT1 monoclonal antibodies. Upregulation of activation-associated markers CD69, CD25 and programmed cell death protein 1 (PD-1) were monitored on activated non-transduced T cells, CAR-15E7 and CARLFTT1 T cells following a 6-hour incubation with K562, K562-HLA-G1 or JEG-3 cell lines. (B) Representative dot plot of the upregulation of CD69 and CD25 on activated non-transduced T cells and CAR-T cells sets. (C) Upregulation of activationassociated markers CD69, CD25 and PD- 1 was determined on CAR expressing T cells (CD8 $/$ trCD19 ${ }^{+}$) in comparison to CAR negative T cells (CD8 ${ }^{+} /$trCD19)$^{-}$) following incubation with K562, K562-HLA-G1 or JEG-3 cell lines ( $n=3$, NT, non-transduced). 
A

K562

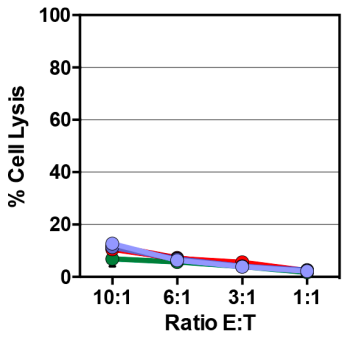

B

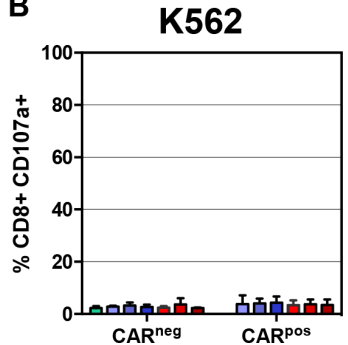

K562-HLA-G1

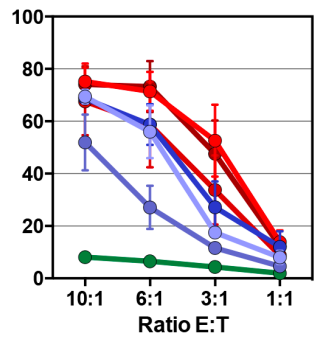

K562-HLA-G1

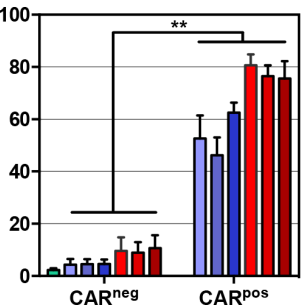

JEG-3

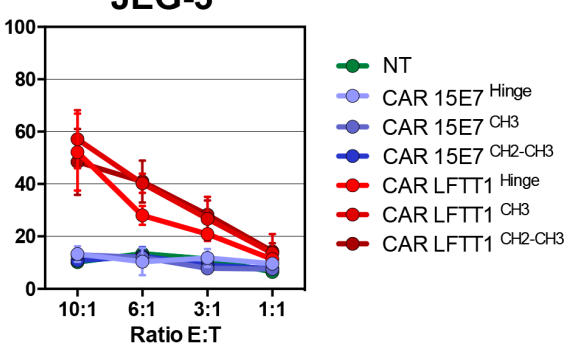

JEG-3

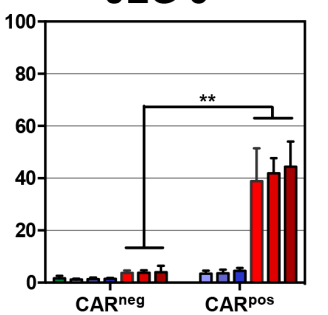

NT
CAR 15E7 Hinge

$\square$ CAR 15E7 ${ }^{\mathrm{CH} 3}$

$\square$ CAR 15E7 ${ }^{\mathrm{CH} 2-\mathrm{CH} 3}$

$\square$ CAR LFTT1 Hinge

CAR LFTT1 1 CHB

CAR LFTT1 1 CH2-CH3

Figure 3 CAR-LFTT1 and CAR-15E7 are cytotoxic against HLA-G1 tumor cells. (A) K562, K562-HLA-G1 or JEG-3 tumor target cells were exposed to activated non-transduced T (NT) cells, CAR-15E7 or CAR-LFTT1 T cells sets at different E:T ratio. Target cells were labeled with CFSE and \% of tumor cell lysis represent the percentage of CFSE ${ }^{+}$cells labeled with live/dead at 24 hours posteffector exposure $(n=6)$. Significance was determined using a Mann-Whitney $U$ test of unpaired $t-t e s t ~\left({ }^{*} p<0,05\right.$; $\left.{ }^{\star *} \mathrm{p}<0002\right)(\mathrm{n}=6)$. (B) CD107a degranulation of CAR-LFTT1, CAR-15E7 sets or activated NT human T cells was monitored on $\mathrm{CD}^{+} / \mathrm{trCD} \mathrm{g}^{+} \mathrm{T}$ cells following 6 hours exposure to K562, K562-HLA-G1 and JEG-3 cells at a E:T ratio of 10:1 ( $\mathrm{n}=6$ ).

All CAR-T cells behaved similarly, regardless of hinge. No upregulation of CD25, CD69 or PD-1 was observed in control conditions.

In cytotoxicity assays (figure 3A), while no lysis was detected in control conditions, CAR-LFTT1-set T cells were cytotoxic against both K562-HLA-G1 and JEG-3 cells that both express $\beta 2 \mathrm{~m}$-associated isoforms, whereas CAR15E7-set T cells were cytotoxic only against K562-HLA-G1 cells, the only cells that express $\beta 2 \mathrm{~m}$-free isoforms. Independently on the HLA-G isoform targeted, CAR-T cells with classical hinge (CAR-LFTT1 and CAR-15E7) and with CH2-CH3 hinge (CAR-LFTT1 ${ }^{\mathrm{CH} 2-\mathrm{CH} 3}$ and CAR$15 \mathrm{E} 7^{\mathrm{CH} 2-\mathrm{CH} 3}$ ) showed similar cytotoxicity, whereas that of CAR-T cells with the $\mathrm{CH} 3$ hinge (CAR-LFTT ${ }^{\mathrm{CH} 3}$ and CAR$15 \mathrm{E} 7^{\mathrm{CH} 3}$ ) was lower in the six independent experiments. CD107a upregulation was investigated to gain insight in the proportion of CAR-T cells actually performing a cytotoxic function after being activated by targets. As shown in figure 3B, CAR-LFTT1 T cells increased CD107a expression when stimulated by HLA-G1/ $\beta 2 \mathrm{~m}$-associated expressing cells $(75 \% \pm 2.7 \%$ against K562-HLA-G1 cells, $44 \% \pm 4 \%$ against JEG-3 cells), whereas CAR-15E7 T cells displayed CD107a only when stimulated by HLA-G1/ $\beta 2 \mathrm{~m}$-free K562-HLA-G1 cells $(62 \% \pm 1.5 \%)$. No impact of hinge was observed.

Together, these results indicate that anti-HLA-G CARLFTT1 and CAR-15E7 T cells are specifically activated by, and cytotoxic against cells expressing the HLA-G isoforms that the LFTT1 and 15E7 mAbs recognize. All three hinges allowed cytotoxic function, even though CAR-T cells based on CH3 hinge were less efficient than CAR-T cells using the classical and CH2-CH3 hinges.

\section{Anti-HLA-G CAR-T cells differentiate into long-term effector memory cells on repeated stimulations}

Anti-HLA-G CAR-T cells demonstrated both specificity and efficiency after a single stimulation by HLA-G1expressing target cells. Next, we studied their differentiation after repeated stimulations. For this, anti-HLA-G CAR-T cells were repeatedly stimulated every 12 days with K562-HLA-G1 cells (figure 4A). Expression of CD62L and CD45RA differentiation markers on CAR-T cells was monitored by flow cytometry prior to, and 24 hours after stimulation (figure 4B). CAR-T IFN $\gamma, \mathrm{TNF} \alpha$ and IL-2 secretion was monitored at days 13, 26 and 39. After Stim-1, CAR-15E7 $7^{\mathrm{CH} 3}$ could not control K562-HLA-G1 cells proliferation.

Prior to stimulation with HLA-G1-expressing cells (Stim0 ), activated non-transduced and anti-HLA-G CAR-T cells contained: CD62 $\mathrm{L}^{+} \mathrm{CD} 45 \mathrm{RA}^{-}$central memory (TCM) cells (>50\%), CD62L-CD45RA ${ }^{-} \mathrm{T}$ effector memory (TEM) cells $(<30 \%)$, few remaining $\mathrm{CD}_{2} 2 \mathrm{~L}^{+} \mathrm{CD} 45 \mathrm{RA}^{+}$naïve $\mathrm{T}$ cells $(10 \%)$ and barely detectable $(<1 \%)$ effector memory RA T cells (TEMRA). From the first to third stimulation, both CAR-LFTT1 and CAR-15E7 presented the same differentiation profile: a predominant TEM population $(>60 \%)$, a contraction of the TCM population $(<30 \%)$, an almost extinction of the CD25 CD69- population and the induction of a small population of TEMRA cells (figure 4B,C).

CAR-LFTT1 displayed more TCM than the CARLFTT1 ${ }^{\mathrm{CH} 2-\mathrm{CH} 3}$, which differentiated in TEM after repeated stimulations. All CAR-LFTT1 sets secreted IFN $\gamma, \mathrm{TNF} \alpha$ and IL-2 cytokines (figure 4D). For both CAR-LFTT1 and CAR-LFTT1 ${ }^{\mathrm{CH} 2-\mathrm{CH} 3}$, IFN $\gamma$ secretion was strongly induced after Stim-1 and then remained stable, IL-2 
A

Repeated 3 times (12 days intervals)

CD3/CD28 Activation
D-2

D-2

$\begin{array}{ccc}\text { D0 } & \text { D11 } & \text { D13 } \\ \text { Transduction } & \text { Phenotype analysis } & \text { Cytokines secretion assay }\end{array}$

B

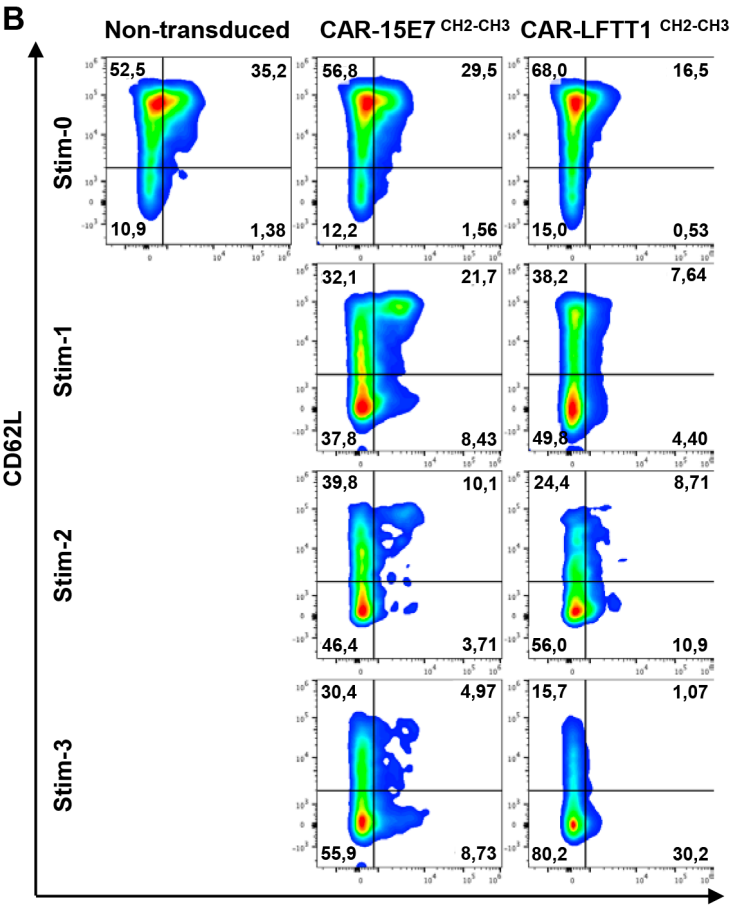

CD45RA
C

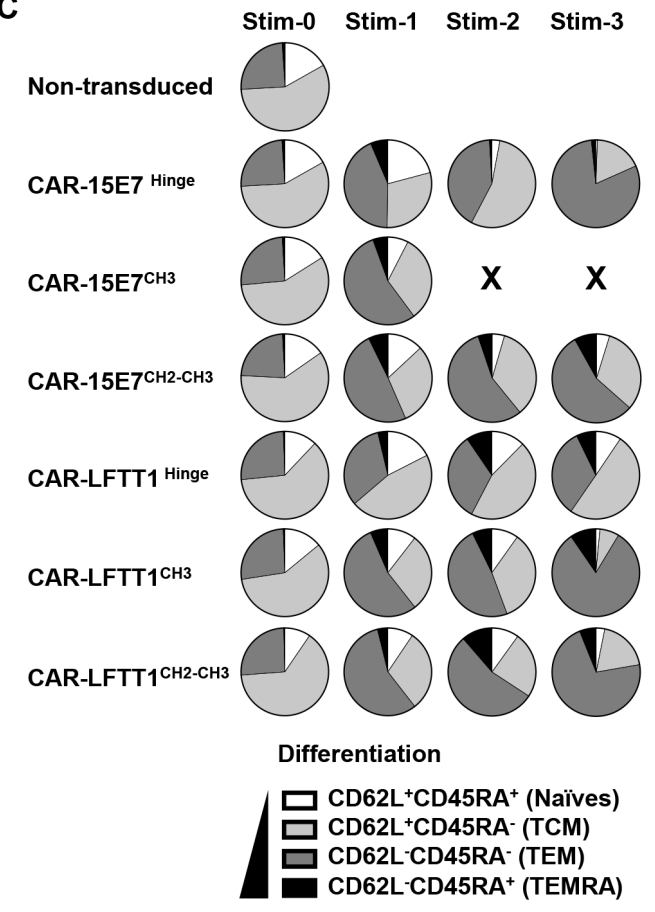

D
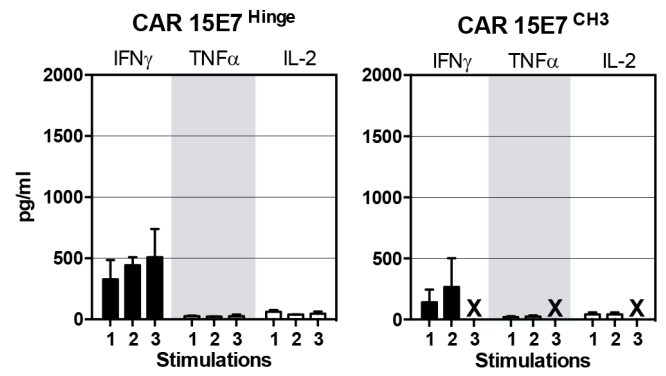

CAR 15E7 ${ }^{\mathrm{CH} 2-\mathrm{CH} 3}$

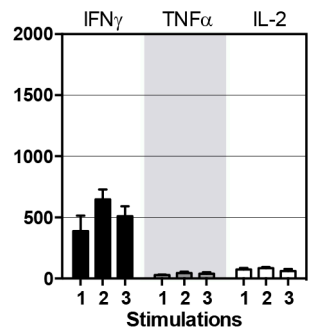

CAR LFTT1 1 Hinge
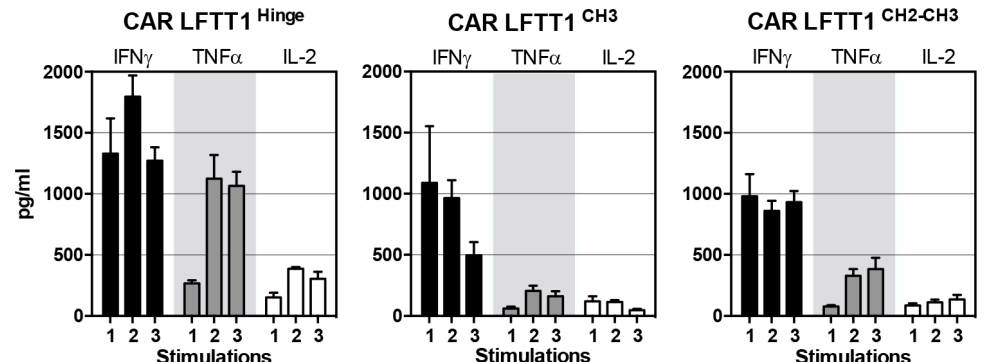

Figure 4 Anti-HLA-G CAR-T cells differentiated into long-term memory effector cells after repeated stimulation with HLA-G tumor cells. (A) Schematic representation of anti-HLA-G CAR-T cells repeated stimulation with K562-HLA-G1 tumor cells. Transduced CAR-LFTT1, CAR-15E7 sets or activated non-transduced T cells were repeatedly stimulated every 12 days with K562-HLA-G1 cells at a 10:1 E:T ratio. Expression of differentiation markers was monitored prior to and 24 hours after the stimulation and cytokines secretion levels were monitored at days 13, 26 and 39. (B) Representative flow cytometry analysis of the expression of CD62L and CD45RA differentiation markers on activated non-transduced, CAR-15E7 and CAR-LFTT1 T cells prior to and 24 hours after stimulations rounds. (C) Day prior stimulation and after each repeated stimulation with K562-HLA-G1 cells, differentiation of T cells was determined on the basis of their CD62L/CD45RA cell-surface expression. CAR-T cells were gated on CD8 and trCD19 reporter co-expression. (D) Co-culture medium was recovered the day after each stimulation with K562-HLA-G1 cells and analyzed for interferon (IFN) $\gamma$, interleukin (IL)-2 and tumor necrosis factor (TNF) $\alpha$ concentration ( $n=3$ ). Columns represent mean \pm SEM. For each panel, after first stimulation round, activated non-transduced T cells were removed from the experiment due to absence of cytotoxicity against K562-HLA-G1 cells. 
secretion strongly increased between Stim-1 and Stim-2, and $\mathrm{TNF} \alpha$ secretion was increased between Stim-1 and Stim-2. CH2-CH3 hinge secreted lower levels of these cytokines compared with classical hinge. Even though CAR-LFTT1 ${ }^{\mathrm{CH} 3}$ secreted IFN $\gamma$ after Stim-1, this secretion dramatically decreased along repeated stimulations. Also, IL-2 secretion for the CH3 hinge was weaker than for the classical or $\mathrm{CH} 2-\mathrm{CH} 3$ hinges, and $\mathrm{TNF} \alpha$ secretion was barely detectable. For CAR-15E7 sets, IFN $\gamma$ secretion also increased between Stim-1 and Stim-2 for all hinges, but its level was weaker than that of the CAR-LFTT1 sets. IL-2 and TNF $\alpha$ secretions were almost not detected for CAR$15 \mathrm{E} 7$ sets.

\section{Anti-HLA-G CAR-T cells function is not inhibited by HLA-G:ILT2 interaction}

Targeting HLA-G with CAR-T cells makes sense only if anti-HLA-G CAR-T cells are not inhibited by HLA-G itself. HLA-G inhibits T cells through the ILT2 receptor. Thus, unresponsiveness to HLA-G would occur if (i) antiHLA-G CAR-T cells did not express ILT2, or if (ii) antiHLA-G CAR-T cells were insensitive to HLA-G inhibition, or both.

Ten per cent to $20 \%$ of circulating $\mathrm{CD} 8^{+} \mathrm{T}$ cells express ILT2 in young healthy individuals, and this proportion increases with age. In patients with bladder cancer, $\mathrm{CD}^{+} \mathrm{ILT}^{+} \mathrm{T}$ cells were shown to represent up to $80 \%$ of total CD8 ${ }^{+} \mathrm{T}$ cells. ${ }^{42} \mathrm{~T}$ cells expressing ILT2 are often antigen-experienced, and were shown to upregulate ILT2 on contact with HLA-G-expressing tumor cells. ${ }^{43}$ Thus, we compared ILT2 cell-surface expression on CAR-T cells before and after repeated stimulation with K562-HLA-G1 . In these experiments, PD-1 expression levels were used as a marker of expanded and reactive T cells. ${ }^{44-47}$ After activation, ILT2 was expressed by $20 \%$ of non-transduced $\mathrm{CD}^{+} \mathrm{T}$ cells, and only by $10 \%$ of CAR-T cells (figure $5 \mathrm{~A}$ ). After three rounds of stimulation, no ILT2 upregulation was observed on $\mathrm{CAR}^{\text {pos }} \mathrm{T}$ cells, whereas a slight increase was observed on $\mathrm{CAR}^{\text {neg }} \mathrm{CD}^{+} \mathrm{T}$ cells $\left(25 \% \mathrm{ILT}^{+} \mathrm{CAR}^{\text {neg }}\right.$ $\mathrm{T}$ cells). By contrast, PD-1 expression was equivalent on both $\mathrm{CAR}^{\text {neg }}$ and $\mathrm{CAR}^{\text {pos }} \mathrm{CD}^{+} \mathrm{T}$ cells prior to stimulation (8\% PD- $\left.1^{+} \mathrm{CAR}^{\mathrm{neg} / \mathrm{pos}}\right)$, and after three stimulations, PD-1 expression was significantly upregulated in the $\mathrm{CAR}^{\text {pos }}$ population only (15\% for CAR-15E7 and $22 \%$ for CARLFTT1) (figure 5B). As expected, ILT2 ${ }^{+} \mathrm{CD}^{+} \mathrm{T}$ cells had a more differentiated phenotype before the first stimulation compared with their negative counterpart. Indeed, prior to stimulation, ILT2 ${ }^{+}$CAR-LFTT1 and CAR-15E7 T cells contained $44 \%$ and $41 \%$ TEM cells, respectively, whereas their ILT2-negative counterparts contained only $23 \%$ and $25 \%$ TEM cells, respectively. However, after three stimulations, most $\mathrm{CAR}^{\mathrm{pos}}-\mathrm{T}$ cells had differentiated into TEM cells and these differences were no longer observable (figure 5C).

In order to determine if anti-HLA-G ILT2 ${ }^{+}$CAR-T cells were capable of lysing HLA-G-positive target cells despite ILT2 cell-surface expression, we isolated and transduced ILT2 $^{+}$and ILT2 ${ }^{-} \mathrm{CD}^{+}{ }^{+} \mathrm{T}$ cells. Transduced cells were then phenotyped and used in cytotoxicity assay against K562-HLA-G1 target cells. As shown in figure 5D, at the time of the assay, ILT2 $\mathrm{CD}^{+} \mathrm{T}$ cells had been efficiently transduced by both LFTT1 and 15E7 CAR constructs (82\% and $81 \%$, respectively), whereas transduction of ILT2 $2^{+} \mathrm{CD}^{+} \mathrm{T}$ cells had been less efficient $(51 \%$ and $36 \%$ of $\mathrm{ILT}^{+} \mathrm{CD}^{+} \mathrm{T}$ cells, respectively). At the end of the cytotoxicity assay, the proportion of $\mathrm{CD} 107 \mathrm{a}^{+}$cells in ILT2-positive and ILT2-negative $\mathrm{CAR}^{\mathrm{pos}} \mathrm{CD}^{+} \mathrm{T}^{+}$cells was identical, for both LFTT1 and 15E7 CAR constructs, indicating that anti-HLA-G CAR-T cells expressing ILT2 had not been inhibited by the HLA-G/ILT2 interaction in terms of cytotoxicity (figure $5 \mathrm{E}$ ) and $\mathrm{T}$ helper 1 cytokines secretion profile (figure $5 \mathrm{~F}$ ).

\section{Anti-HLA-G CAR-T cells in vivo functionality}

We sought to prove that our CAR strategy was suitable for in vivo application. At day 0 , immune-deficient NSG mice were injected intravenously with $10^{6}$ K562-HLA-G1 cells expressing luciferase Firefly reporter protein. At day 3, mice were injected with either $10^{7}$ CAR-LFTT1, CAR-15E7 or control T cells (figure 6A). Tumor progression was monitored by bioluminescence every week. The results for each individual mouse can be seen in figure 6B,C, and results for six mice per group are shown in online supplemental figure 2. Already at day 17, K562-HLA-G1 tumors were detectable in all mice of the control group, but only in one mouse from CAR-15E7 and CAR-LFTT1 groups. At day 37, three out of six mice of the CAR-15E7 group, and five out of six in the CAR-LFTT1 group were still tumorfree. At day 57, only one mouse in the CAR-15E7 group, but still five out of six in the CAR-LFTT1 group were tumor-free. This demonstrated that CAR-15E7 T cells had delayed tumor growth by about 2 weeks, whereas CARLFTT1 $\mathrm{T}$ cells had efficiently eradicated K562-HLA-G1 cells in vivo.

\section{DISCUSSION}

Despite exceptional promises in the treatment of cancer, adoptive $\mathrm{T}$ cell therapies are still impaired by (i) the lack of TSA, especially some that would be common to multiple/most tumor types ${ }^{5}$ and (ii) tumor expression of ICPs inhibiting antitumor immune responses, even those of CAR-T cells. Anti-ICP CAR-T cell therapy would take advantage of already implemented antibody-based immune therapies (eg, PD-1/PD-L1), but the lack of tumor-specific expression of these molecules raises safety concerns because of 'on target, off tumor' effects. ${ }^{48}$ This might not apply to HLA-G. Indeed, HLA-G is special among ICPs because notwithstanding its broad inhibitory function, its physiological expression is mainly fetal. Consequently, HLA-G is absent in most adult tissues while most tumor types neo-express it to various degrees. ${ }^{25}$ In patients with cancer, this makes of HLA-G a de facto TSA, and so effectively a tumor-specific ICP. For monomorphic ICP molecules, the difference between 'TSA' and 'tumor-specific ICP' might not exist, but for HLA-G, 


\section{A}

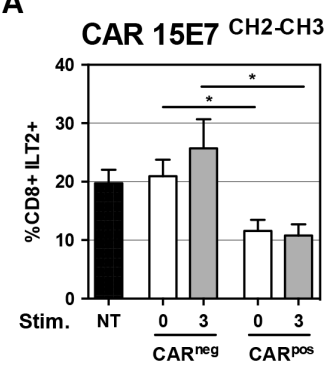

B

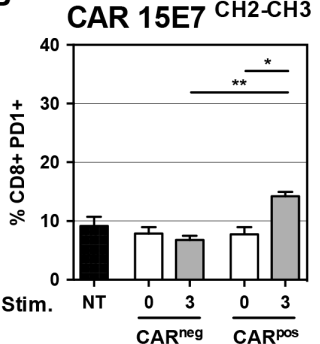

CAR LFTT1 $1{ }^{\mathrm{CH}} 2-\mathrm{CH} 3$

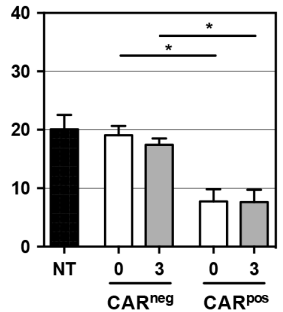

CAR LFTT1 1 CH2-CH3

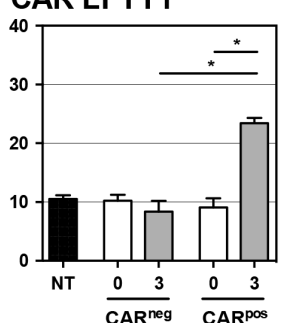

C

CAR 15E7 ${ }^{\mathrm{CH} 2-\mathrm{CH} 3}$

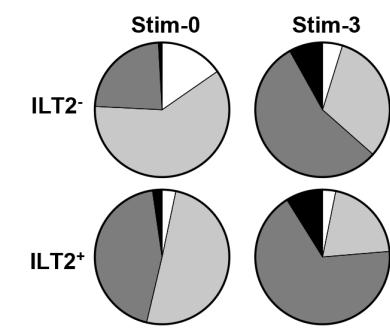

CAR LFTT1 ${ }^{\mathrm{CH} 2-\mathrm{CH} 3}$

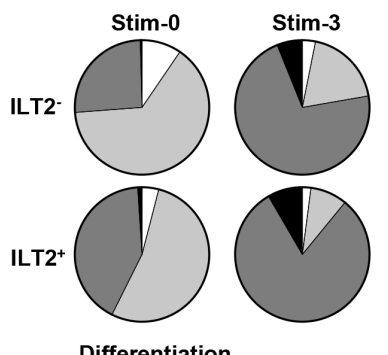

fferentiation

(口 CD62L+CD45RA+ (Naïves) 口 CD62L+CD45RA- (TCM) $^{+}$ CD62L-CD45RA- (TEM) CD62L-CD45RA+ (TEMRA)

D
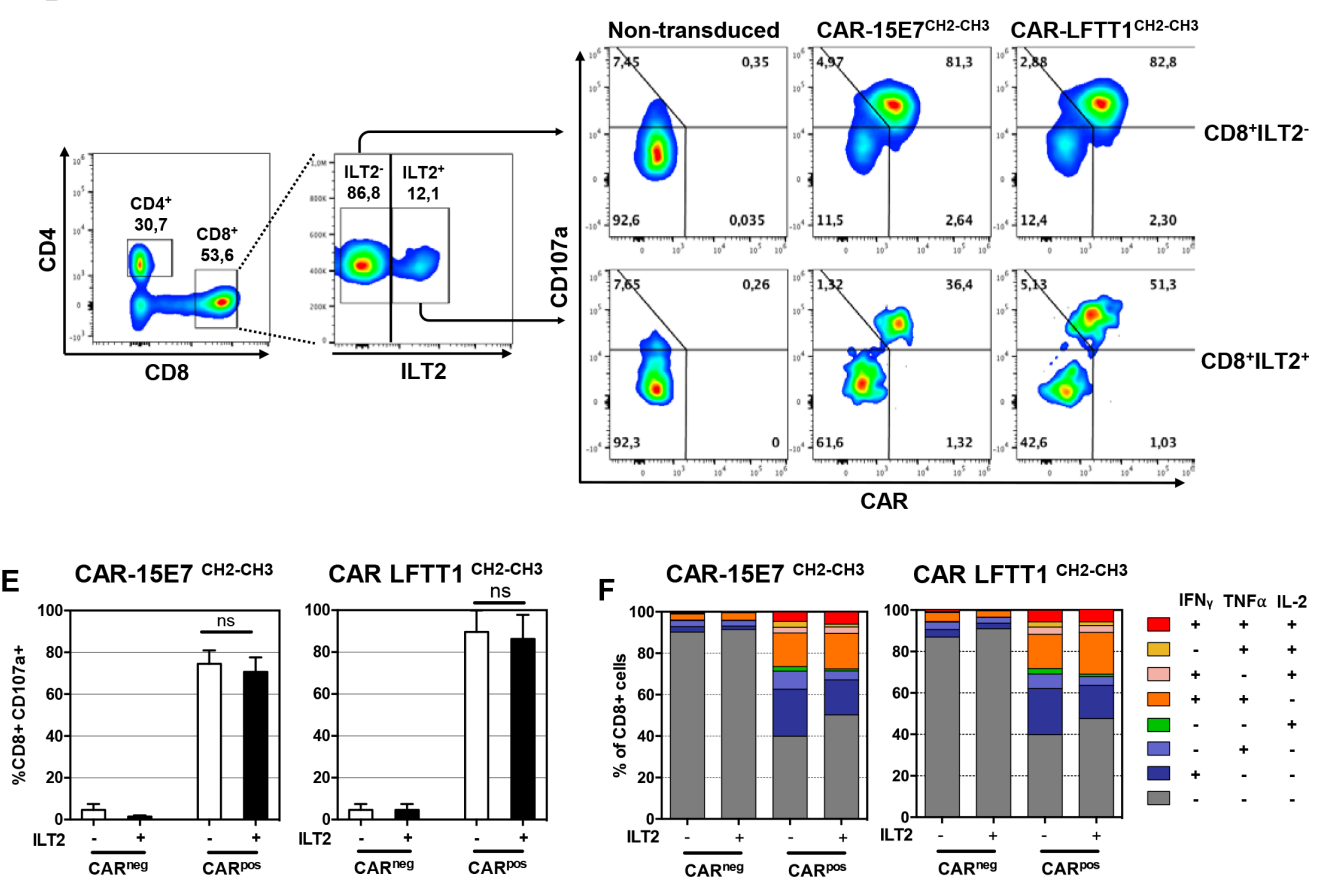

Figure 5 Anti-HLA-G CAR-T cells are not inhibited by ILT2 expression. Following transduction of T cells, CAR-T cells displaying or not the CAR construct at their surface (respectively CAR ${ }^{\text {pos }}$ and CAR ${ }^{\text {neg }} T$ cells) were analyzed for their ILT2 and programmed cell death protein 1 (PD-1) cell-surface expression after repeated stimulation with K562-HLA-G1 cells at a 10:1 E:T ratio. $\mathrm{CH} 2-\mathrm{CH} 3$ hinge was used to determine the CAR cell-surface expression CAR-LFTT1 or CAR-15E7 T cells. (A) ILT2 expression levels on $\mathrm{CAR}^{\text {neg/pos }}$ cells prior and after repeated stimulations with K562-HLA-G1 were compared with activated non-tranduced (NT) T cells. (B) PD-1 expression levels on CAR ${ }^{\text {neg/pos }}$ cells prior and after repeated stimulations with K562HLA-G1 were compared with activated NT T cells. Significance was determined using a Friedmann test $\left({ }^{*} \mathrm{p}<0,05 ;{ }^{* *} \mathrm{p}<0002\right)$ $(n=6)$. (C) Differentiation of CAR-15E7 and CAR-LFTT1 T cells expressing or not ILT2 was determined on the basis of their CD62L/CD45RA expression on CAR ${ }^{\text {pos }} T$ cells before and after the repeated stimulations with K562-HLA-G1 cells. (D) 15E7 ${ }^{\mathrm{CH} 2-}$ ${ }_{\mathrm{CH} 3}$ or LFTT1 ${ }^{\mathrm{CH} 2-\mathrm{CH} 3}$ CAR-T cells were generated from ILT2 ${ }^{+}$and ILT2 ${ }^{-}$sorted human $\mathrm{CD} 8^{+} \mathrm{T}$ cells before being co-cultured with K562-HLA-G1 cells. (E) CD107a degranulation of ILT2 ${ }^{-/+}$CAR $^{\text {neg/pos }}$ T cells was monitored by labeling of CD107a at the surface of $\mathrm{CAR}^{\text {neg/pos }} \mathrm{CD}^{+} / \mathrm{trCD} 19^{+} \mathrm{T}$ cells after 6 hours exposure to K562-HLA-G1 target cells. Columns represent means $\pm \mathrm{SEM}$. Significance was determined using a Mann-Whitney $U$ test (ns, non significative) ( $n=3$ ). (F) ILT2 expression impact on antiHLA-G CAR ${ }^{\text {neg/pos }} T$ cells. T helper 1 cytokines expression profile was evaluated after 18 hours co-incubation with K562-HLA-G1 cells. Cytokines (interferon (IFN) $\gamma$, tumor necrosis factor (TNF) $\alpha$, IL-2) secretion by CAR ${ }^{\text {neg/pos }} \mathrm{CD}^{+}$cells was determined by FACS and proportion of each combination are represented in cumulative histograms. 
A

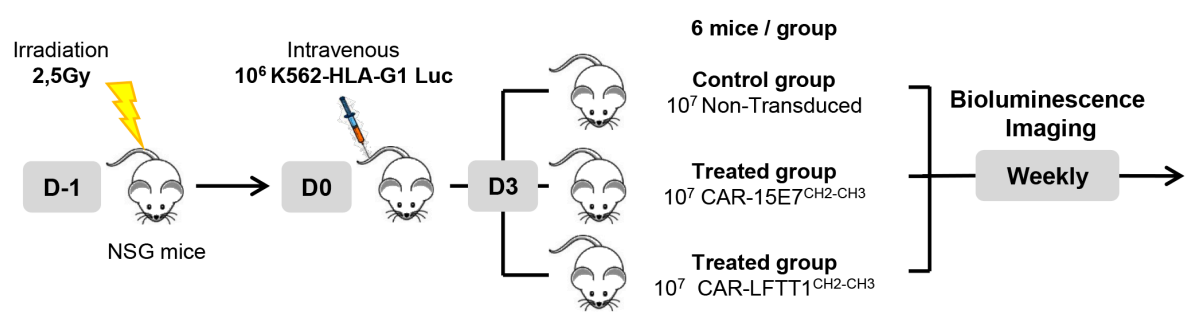

B

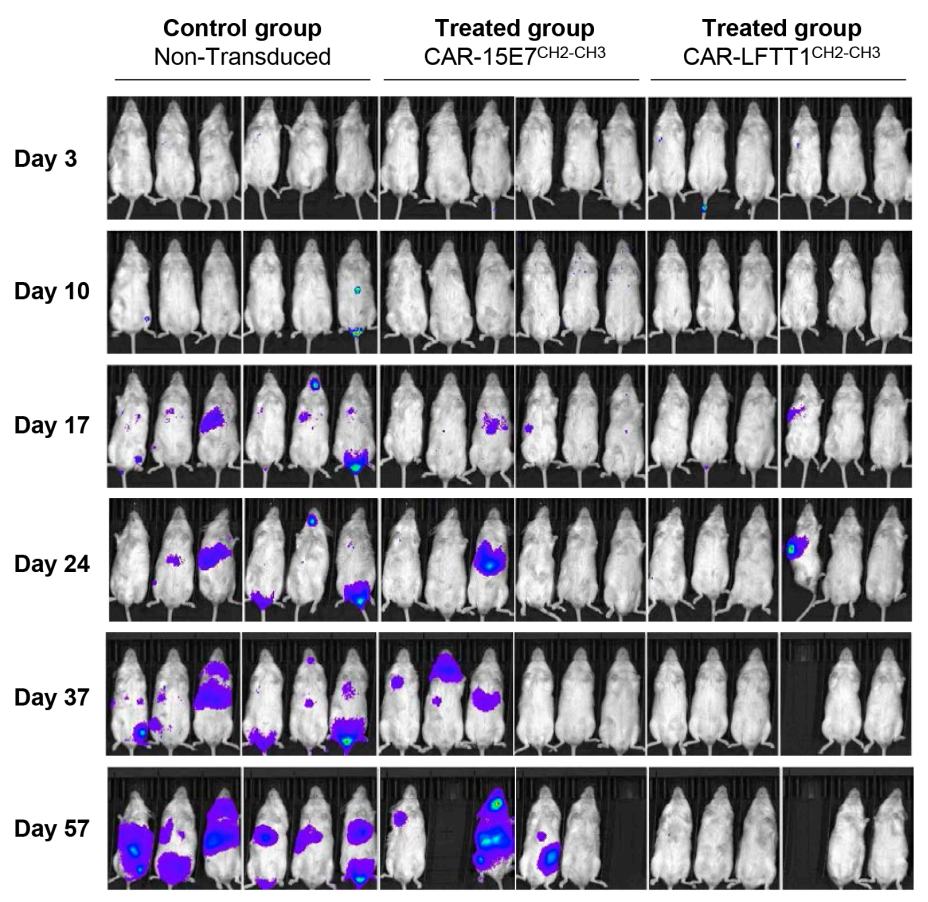

C

Control group Non-Transduced

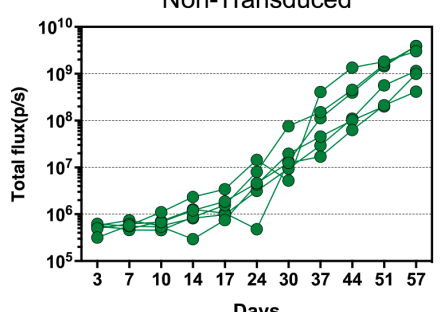

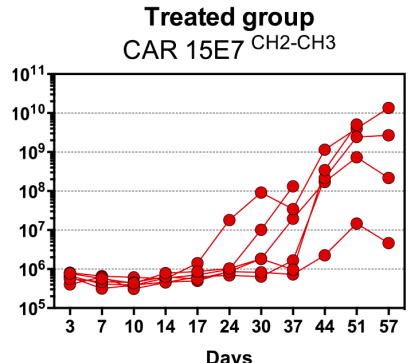

Days

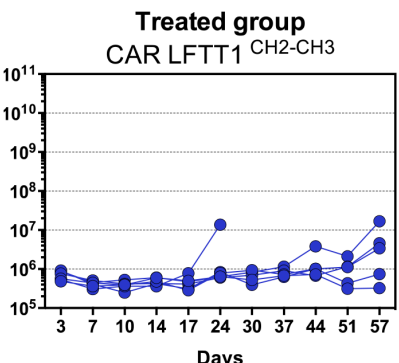

Days

Figure 6 Anti-HLA-G CAR-T cells mediated tumor control of K562-HLA-G1-luciferase mouse model. (A) Schema of experimental procedure: NOD/SCID/IL-2R $\gamma c$-deficient (NSG) mice were irradiated the day before being intravenously injected with $10^{6}$ K562-HLA-G1-luciferase cells (K562-HLA-G1-Luc). Mice received activated non-transduced T cells or CAR-T (CAR$15 E 7^{\mathrm{CH} 2-\mathrm{CH} 3}$ or CAR-LFTT1 ${ }^{\mathrm{CH} 2-\mathrm{CH} 3}$ ) cells on day 3 and were monitored by bioluminescence imaging over time. (B) Representative bioluminescence intensity of mice over time. (C) Total flux of each mouse in the three groups at different points.

it is a key issue because it is a complex molecule with several isoforms, not all of them associated with $\beta 2 \mathrm{~m}$, not all of them inhibitory, and not all of them functionally described.

Thus, in the design of anti-HLA-G CAR constructs, we aimed at targeting the known ICP function of HLA-G by restricting our targets to isoforms known to be inhibitory through interaction with ILT2 ( $\beta 2 \mathrm{~m}$-associated HLA-G1/HLA-G5) or ILT4 ( $\beta 2 \mathrm{~m}$-free HLA-G1/HLAG5, and HLA-G2/HLA-G6). Thus, new antibodies were generated for the paratope design of CARs. LFTT1 recognizes the $\alpha 1$ domain of $\beta 2 \mathrm{~m}$-associated HLA-G isoforms, as do other antibodies such as MEM-G/9 or $87 \mathrm{G}$. For the generation of $15 \mathrm{E} 7$, because the structures of $\beta 2 \mathrm{~m}$-free isoforms may vary, we targeted a unique motif of the ILT4interacting sequence (HPVFDYEATL) located in the HLA-G- $\alpha 3$ domain. ${ }^{50}$ By targeting the $\alpha 3$ domain, even newly described isoforms not containing an $\alpha 1$ domain $^{37}$ may be targeted. 
Both anti-HLA-G CAR-T cell sets specifically recognized, got activated by, and lysed their cognate HLA-G isoforms expressed by targeted tumor cells. Although CAR-LFTT1 $\mathrm{T}$ cells were more efficient than CAR-15E7 T cells in our experimental models, CAR-15E7 T cells interest resides in targeting tumor cells expressing HLA-G2 and/or HLA-G new isoforms, devoid of $\beta 2 \mathrm{~m}$ and/or $\alpha 1$ domain but engaging ILT2/ 4 via their $\alpha 3$ domain. Also, the development of bispecific CAR-T cells, combining their respective $\mathrm{scFv}$ specificities, would allow recognition of the full repertoire of immunosuppressive HLA-G isoforms, and avoid a possible escape from CAR-LFTT1 $\mathrm{T}$ cells through downregulation of the $\beta 2 \mathrm{~m}$ by tumor cells. ${ }^{51-53}$

CAR-T cell-based immunotherapies rely on persistence of their function over time after administration. We demonstrate that both CAR-LFTT1 and CAR-15E7 T cells differentiated mainly in TCM cells, which have been associated with greater in vivo antitumor activity and persistence. ${ }^{54}$ Concerning the cytokine secretion profile, CAR-LFTT1 T cells showed a significant increase of IL-2 secretion between first and second stimulation likely related to a stronger activation following antigen stimulation and higher proliferation, resulting in an enrichment of the most responsive T cells. Rossi et al determined that a polyfunctional phenotype of CAR-T cells, with increased IL-2, IFN $\gamma$ and TNF $\alpha$ secretion, is associated with better clinical outcome in patients treated with anti-CD19 CAR-T cells in non-Hodkgin's lymphoma. ${ }^{55}$ Therefore, for CAR-LFTT1, the construct based on a classical hinge that demonstrated a stronger secretion of IFN $\gamma$, IL-2 and $\mathrm{TNF} \alpha$ cytokines levels in comparison to $\mathrm{CH} 3$ and $\mathrm{CH} 2-$ CH3 hinges might be the best choice for clinical use. Regarding CAR-15E7 T cells, increasing the flexibility or the access to the membrane-proximal HLA-G- $\alpha 3$ domain with extended hinges did not improve the functionality. CAR-15E7 T cells activation after K562-HLA-G1 stimulation appeared less efficient than CAR-LFTT1 $\mathrm{T}$ cells. However, it is important to note that the K562-HLA-G1 cells used as model to test both CARs, express more $\beta 2 \mathrm{~m}$ associated HLA-G1 than $\beta 2 \mathrm{~m}$-free isoforms, favoring CAR-LFTT1 T cells cytotoxicity. CAR-15E7 T cells efficiency should be determined in a more controlled $\beta 2 \mathrm{~m}$ free system, to model the commonly observed context of tumors in which $\beta 2 \mathrm{~m}$ is downmodulated. Given these, anti-HLA-G CAR-T cells clinical trial phase I will be based on the classical hinge with the LFTT1 paratope.

A major hurdle for CAR therapeutic application is T cell inhibition by ICP. ILT2 is expressed by some $\mathrm{CD} 8^{+} \mathrm{T}$ cells, and upregulated following cytotoxic T cell activation. ${ }^{43}$ ILT2 exerts its inhibitory function through four immunoreceptor tyrosine-based inhibitory (ITIM) motifs, ${ }^{56}$ while CAR cytoplasmic signaling pathway relies on tyrosinebased activating motifs (ITAM) motifs of CD $3 \zeta .^{40}$ Therefore, it was possible that HLA-G $\mathrm{G}^{+}$targets could inhibit CAR-T cytotoxic function through ILT2 engagement. This is most relevant on two fronts: (i) ILT2 expression is upregulated on stimulation and therefore anti-HLA-G CAR T cells could also upregulate it, becoming sensitive to inhibition by HLA-G and (ii) $\mathrm{ILT}^{+} \mathrm{CD} 8^{+} \mathrm{T}$ cells might be present in the PBMC used for transduction since this population increases with age, representing sometimes $>80 \%$ of CD8 T cells, and since patients with cancer are often elderly. Here, we demonstrated that ILT2 expression might not be a problem, eventually. First, during generation of CAR-T cells, CD $8^{+} \mathrm{ILT}_{2}{ }^{+}$population showed a lower transduction efficacy (50\%) compared with ILT2T cells (83\%), explained by the fact that ILT2 expression is associated with a downregulation of $\mathrm{CD} 28,{ }^{57}$ resulting in a suboptimal activation by CD3/CD28 beads and a lower transduction efficiency. Second, after chronic stimulation, ILT2 was not upregulated on resting CAR-T cells, unlike PD-1. Third, the presence of ILT2 did not affect CAR-T cell cytotoxicity, meaning that HLA-G:ILT2 signaling did not inhibit CAR activation signaling. This could be explained by a higher expression level of CAR at the membrane of T cells compared with ILT2 due to $\mathrm{EF} 1 \alpha$, a strong promoter in human $\mathrm{T}$ cells, ${ }^{35}$ or by the fact that the affinity of the original antibodies for HLA-G (Kd $<5 \mathrm{nM})$ is 100 times higher than that of ILT2 $(\mathrm{Kd}<50 \mu \mathrm{M})$ (online supplemental figure 1)..$^{58}$

In tumors, soluble HLA-G molecules (secreted or shed) may be present. Thus, it can be argued that such cell-free HLA-G molecules could decrease anti-HLA-G CAR-T cell functions by interacting with their ILT2. As shown in this manuscript, HLA-G:ILT2 interaction was not sufficient to affect CAR-T cell function. Alternatively, cell-free HLA-G could bind to the CAR construct and block its interaction with membrane-bound HLA-G from tumor cells. The cell lines used here, JEG-3 and K562-HLA-G1, secrete soluble HLA-G and shed membrane HLA-G isoforms, ${ }^{5960}$ but anti-HLA-G CAR-T cells lysed those targets anyway in vitro and in vivo. This indicates that in patients, soluble HLA-G released by tumors is unlikely to act as a decoy and significantly block anti-HLA-G CAR-T cell functions.

HLA-G is also involved in the generation of a tumor tolerogenic microenvironment through regulatory cells: its expression is correlated with accumulation of MDSC, ${ }^{61}$ increased $\mathrm{CD}_{4}{ }^{+} \mathrm{CD} 25^{+} \mathrm{FoxP}^{+}$population ${ }^{62}$ and secretion of IL-10 and TGF- $\beta$ that are responsible for the TME maintenance. ${ }^{17}$ Furthermore, HLA-G is expressed by tolerogenic immune cells such as CD4 ${ }^{+}$FoxP3 ${ }^{-}$HLA- $^{+}$Treg, ${ }^{63}$ suppressive NK cells, ${ }^{30}$ DC-10 cells,${ }^{64}$ infiltrating monocytes $^{65}$ and tumor-associated macrophages (TAM) ${ }^{6667}$ all involved in the TME. We did not formally demonstrate in the present manuscript that anti-HLA-G CAR-T cells were capable of killing real ex vivo tolerogenic HLA-Gexpressing cells such as DC-10 cells. However, in order to demonstrate the possibility that they do, we tested in vitro anti-HLA-G CAR-T cells on LCL-HLA-G1 cells whose immune regulatory functions have been previously demonstrated ${ }^{6869}$ and on the myeloid cell line KG1 transduced with HLA-G1 before and after differentiation in monocyte-derived DC. ${ }^{70}$ In these three cases, anti-HLA-G CAR-T cells lysed HLA-G-expressing cells, but not their HLA-G-negative controls (online supplemental figure $3)$. This demonstrates that the capability of anti-HLA-G 
CAR-T cells to lyse HLA-G-expressing regulatory cells is a real possibility. In this context, anti-HLA-G CAR-T cells could target HLA-G-expressing tumor cells and HLA-Gpositive suppressive cells, potentially allowing the treatment of tumors for which immunosuppressive TME could represent a major issue.

Rossig et al have recently developed a CAR-NK therapy against GD2 in Ewing sarcoma, ${ }^{71}$ but in vivo experiments showed that CARs failed to eliminate GD2-expressing EwS xenografts. Histopathology analysis revealed upregulation of HLA-G in tumor autopsies. ${ }^{72}{ }^{73}$ Supporting the relevance of this finding, co-incubation of NK cells with EwS cells induced upregulation of ILT2 ${ }^{72}$ It is therefore possible that in this instance, the HLA-G:ILT2 interaction inhibited CAR-T cells, causing treatment failure. This is an example where the combinatory therapy with antiHLA-G CAR-T cells may cancel the immune-resistance generated by the TME. Strikingly, tumors can escape from the immune response if only $10 \%$ of tumor cells express HLA-G. ${ }^{74}$ Thus, patients could benefit from anti-HLA-G CAR-T cell therapy even in tumors with low/heterogeneous HLA-G expression strengthening the case for targeting HLA-G in new combinatory immunotherapies.

Altogether, we report here the first anti-HLA-G CAR-T cells targeting HLA-G which is both a TSA and an ICP. Since HLA-G is expressed on both tumors and suppressive immune cells in the TME, anti-HLA-G CAR-T cells would participate in the elimination of both, improving infiltration of anti-HLA-G CAR-T cells and TILs in the tumor.

\section{Author affiliations}

${ }^{1}$ Preclinical Department, Invectys, Paris, France

${ }^{2}$ Molecular Virology and Vaccinology Unit, Virology Department, Pasteur Institute, Paris, Île-de-France, France

${ }^{3}$ INSERM UMR1098 RIGHT Interactions hôte-greffon-tumeur - Ingénierie Cellulaire et Génique, Besancon, Franche-Comté, France

${ }^{4}$ Université Bourgogne Franche-Comté, Besançon, France

${ }^{5}$ Etablissement Français du Sang Bourgogne Franche-Comté, Besançon, France

${ }^{6}$ Service de Recherche en Hémato-Immunologie (SRHI), CEA, Paris, France

${ }^{7}$ Université de Paris, Paris, Île-de-France, France

Acknowledgements The authors would like to thank Dr Patrick England (Institut Pasteur, Paris) for the SPR analysis of $15 \mathrm{E} 7 \mathrm{mAb}$. The authors would also like to thank the animal technicians for their expertise in animal care and management. The authors would like to thank Dr. Claire Germain for cytometry analysis and the animal technicians for their expertise in animal care and management.

Contributors FA, EB-R, JLM, MLe, JMC and PS performed the experiments; FA, EB-R, MLe and ME analyzed data; FA and ME performed statistical analysis; JLM, JC, PS, FG, OA, PL-D, MLo and JC provided guidance and expertise in their respective areas of study. FA, JLM, EB-R, MLo and JC wrote the manuscript; MLo and $\mathrm{JC}$ supervised research. All authors provided input, edited and approved the final version of the manuscript.

Funding The authors have not declared a specific grant for this research from any funding agency in the public, commercial or not-for-profit sectors.

Competing interests None declared.

\section{Patient consent for publication Not required.}

Ethics approval Peripheral blood cell samples of healthy donors were collected at the French Blood Center (EFS BFC, Besançon, France) after obtaining written informed consent. Blood samples collection was approved by the French Ministry of Higher Education and Research (agreement number \#AC-2015-2408, May 22, 2015). All experimental studies complied with European legislation and were approved by local (Animal Ethics Committee of Besançon (Comité d'Ethique Bisontin en Experimentation Animale)) and national (French Ministry of Higher Education and Research (Ministère de l'Education Nationale, de I'Enseignement Supérieur et de la Recherche)) authorities for the care and use of animals.

Provenance and peer review Not commissioned; externally peer reviewed.

Data availability statement Data are available on reasonable request. Data could be available on request to julien.caumartin@invectys.com.

Supplemental material This content has been supplied by the author(s). It has not been vetted by BMJ Publishing Group Limited (BMJ) and may not have been peer-reviewed. Any opinions or recommendations discussed are solely those of the author(s) and are not endorsed by BMJ. BMJ disclaims all liability and responsibility arising from any reliance placed on the content. Where the content includes any translated material, BMJ does not warrant the accuracy and reliability of the translations (including but not limited to local regulations, clinical guidelines, terminology, drug names and drug dosages), and is not responsible for any error and/or omissions arising from translation and adaptation or otherwise.

Open access This is an open access article distributed in accordance with the Creative Commons Attribution Non Commercial (CC BY-NC 4.0) license, which permits others to distribute, remix, adapt, build upon this work non-commercially, and license their derivative works on different terms, provided the original work is properly cited, appropriate credit is given, any changes made indicated, and the use is non-commercial. See http://creativecommons.org/licenses/by-nc/4.0/.

\section{ORCID iDs}

Olivier Adotevi http://orcid.org/0000-0002-7742-136X

Julien Caumartin http://orcid.org/0000-0001-5769-6342

\section{REFERENCES}

1 Park JH, Rivière I, Gonen M, et al. Long-Term follow-up of CD19 CAR therapy in acute lymphoblastic leukemia. N Engl J Med 2018;378:449-59.

2 Ying Z, Huang XF, Xiang X, et al. A safe and potent anti-CD19 CAR T cell therapy. Nat Med 2019;25:947-53.

3 Mullard A. FDA approves first CAR T therapy. Nat Rev Drug Discov 2017;16:669.

4 Mullard A. PRIME time at the EMA. Nat Rev Drug Discov 2017;16:226-8.

5 Maute RL, Gordon SR, Mayer AT, et al. Engineering high-affinity PD-1 variants for optimized immunotherapy and immuno-PET imaging. Proc Natl Acad Sci U S A 2015;112:E6506-14.

6 Xia A-L, Wang X-C, Lu Y-J, et al. Chimeric-antigen receptor T (CAR-T) cell therapy for solid tumors: challenges and opportunities. Oncotarget 2017;8:90521-31.

7 Rafiq S, Hackett CS, Brentjens RJ. Engineering strategies to overcome the current roadblocks in CAR T cell therapy. Nat Rev Clin Oncol 2020;17:147-67.

8 Martinez M, Moon EK. Car T cells for solid tumors: new strategies for finding, infiltrating, and surviving in the tumor microenvironment. Front Immunol 2019;10:128.

9 John LB, Devaud C, Duong CPM, et al. Anti-PD-1 antibody therapy potently enhances the eradication of established tumors by genemodified T cells. Clin Cancer Res 2013;19:5636-46.

10 Cherkassky L, Morello A, Villena-Vargas J, et al. Human CAR T cells with cell-intrinsic PD-1 checkpoint blockade resist tumor-mediated inhibition. J Clin Invest 2016;126:3130-44.

11 Gross G, Eshhar Z. Therapeutic potential of T cell chimeric antigen receptors (CARS) in cancer treatment: counteracting Off-Tumor toxicities for safe car T cell therapy. Annu Rev Pharmacol Toxicol 2016;56:59-83.

12 Grosser R, Cherkassky L, Chintala N, et al. Combination immunotherapy with CAR T cells and checkpoint blockade for the treatment of solid tumors. Cancer Cell 2019;36:471-82.

13 Kambhampati S, Gray L, Fakhri B, et al. Immune-Related adverse events associated with checkpoint inhibition in the setting of CAR T cell therapy: a case series. Clin Lymphoma Myeloma Leuk 2020;20:e118-23.

14 McMaster MT, Librach CL, Zhou Y, et al. Human placental HLA-G expression is restricted to differentiated cytotrophoblasts. $\mathrm{J}$ Immunol 1995;154:3771-8.

15 Gregori S, Amodio G, Quattrone F, et al. Hla-G orchestrates the early interaction of human trophoblasts with the maternal niche. Front Immunol 2015;6:128.

16 Ferreira LMR, Meissner TB, Tilburgs T, et al. Hla-G: at the interface of Maternal-Fetal tolerance. Trends Immunol 2017;38:272-86. 
17 Papuchova H, Kshirsagar S, Xu L, et al. Three types of HLA-G+ extravillous trophoblasts that have distinct immune regulatory properties. Proc Natl Acad Sci U S A 2020;117:15772-7.

18 Crisa L, McMaster MT, Ishii JK, et al. Identification of a thymic epithelial cell subset sharing expression of the class Ib HLA-G molecule with fetal trophoblasts. J Exp Med 1997;186:289-98.

19 Le Discorde M, Moreau P, Sabatier P, et al. Expression of HLA-G in human cornea, an immune-privileged tissue. Hum Immunol 2003;64:1039-44.

20 Menier C, Rabreau M, Challier J-C, et al. Erythroblasts secrete the nonclassical HLA-G molecule from primitive to definitive hematopoiesis. Blood 2004;104:3153-60.

21 Cirulli V, Zalatan J, McMaster M, et al. The class I HLA repertoire of pancreatic islets comprises the nonclassical class lb antigen HLA-G. Diabetes 2006;55:1214-22.

22 Nasef A, Mathieu N, Chapel A, et al. Immunosuppressive effects of mesenchymal stem cells: involvement of HLA-G. Transplantation 2007;84:231-7.

23 Huang Y-H, Zozulya AL, Weidenfeller $\mathrm{C}$, et al. T cell suppression by naturally occurring HLA-G-expressing regulatory CD4+ T cells is IL10-dependent and reversible. J Leukoc Biol 2009;86:273-81.

24 Amodio G, Comi M, Tomasoni D, et al. HLA-G expression levels influence the tolerogenic activity of human DC-10. Haematologica 2015;100:548-57.

25 Loustau M, Anna F, Dréan R, et al. Hla-G Neo-Expression on tumors. Front Immunol 2020;11:1685.

26 Carosella ED, Rouas-Freiss N, Tronik-Le Roux D, et al. Hla-G: an immune checkpoint molecule. Adv Immunol 2015;127:33-144.

27 Lin A, Yan W-H. Heterogeneity of HLA-G expression in cancers: facing the challenges. Front Immunol 2018;9:2164.

28 Paul P, Rouas-Freiss N, Khalil-Daher I, et al. Hla-G expression in melanoma: a way for tumor cells to escape from immunosurveillance. Proc Natl Acad Sci U S A 1998;95:4510-5.

29 Carosella ED, Moreau P, Lemaoult J, et al. Hla-G: from biology to clinical benefits. Trends Immunol 2008;29:125-32.

30 Caumartin J, Favier B, Daouya M, et al. Trogocytosis-based generation of suppressive NK cells. Embo J 2007;26:1423-33.

31 LeMaoult J, Caumartin J, Daouya M, et al. Immune regulation by pretenders: cell-to-cell transfers of HLA-G make effector T cells act as regulatory cells. Blood 2007;109:2040-8.

32 Carosella ED, Gregori S, LeMaoult J. The tolerogenic interplay(s) among HLA-G, myeloid APCs, and regulatory cells. Blood 2011;118:6499-505.

33 Agaugué S, Carosella ED, Rouas-Freiss N. Role of HLA-G in tumor escape through expansion of myeloid-derived suppressor cells and cytokinic balance in favor of Th2 versus Th1/Th17. Blood 2011;117:7021-31.

34 Loumagne L, Baudhuin J, Favier B, et al. In vivo evidence that secretion of HLA-G by immunogenic tumor cells allows their evasion from immunosurveillance. Int J Cancer 2014;135:2107-17.

35 Bôle-Richard E, Fredon M, Biichlé S, et al. CD28/4-1BB CD123 CAR T cells in blastic plasmacytoid dendritic cell neoplasm. Leukemia 2020;34:3228-41.

36 Hviid TVF, Hylenius S, Rørbye C, et al. HLA-G allelic variants are associated with differences in the HLA-G mRNA isoform profile and HLA-G mRNA levels. Immunogenetics 2003;55:63-79.

37 Tronik-Le Roux D, Renard J, Vérine J, et al. Novel landscape of HLA-G isoforms expressed in clear cell renal cell carcinoma patients. Mol Oncol 2017;11:1561-78.

38 Carosella ED, Favier B, Rouas-Freiss N, et al. Beyond the increasing complexity of the immunomodulatory HLA-G molecule. Blood 2008;111:4862-70.

39 HoWangYin K-Y, Loustau M, Wu J, et al. Multimeric structures of HLA-G isoforms function through differential binding to LILRB receptors. Cell Mol Life Sci 2012;69:4041-9.

40 Guedan S, Calderon H, Posey AD, et al. Engineering and design of chimeric antigen receptors. Mol Ther Methods Clin Dev 2019;12:145-56.

41 Ramos CA, Rouce R, Robertson CS, et al. In Vivo Fate and Activity of Second- versus Third-Generation CD19-Specific CAR-T Cells in B Cell Non-Hodgkin's Lymphomas. Mol Ther 2018;26:2727-37.

42 Desgrandchamps F, LeMaoult J, Goujon A, et al. Prediction of non-muscle-invasive bladder cancer recurrence by measurement of checkpoint HLAG's receptor ILT2 on peripheral $\mathrm{CD}^{+} \mathrm{T}$ cells. Oncotarget 2018:9:33160-9.

43 LeMaoult J, Zafaranloo K, Le Danff C, et al. HLA-G up-regulates ILT2, ILT3, ILT4, and KIR2DL4 in antigen presenting cells, NK cells, and T cells. Faseb J 2005;19:1-23.

44 Gros A, Robbins PF, Yao X, et al. PD-1 identifies the patient-specific $\mathrm{CD}^{+}$tumor-reactive repertoire infiltrating human tumors. J Clin Invest 2014;124:2246-59.
45 Gros A, Parkhurst MR, Tran E, et al. Prospective identification of neoantigen-specific lymphocytes in the peripheral blood of melanoma patients. Nat Med 2016;22:433-8

46 Simon S, Vignard V, Varey E, et al. Emergence of high-avidity MelanA-Specific Clonotypes as a reflection of anti-PD-1 clinical efficacy. Cancer Res 2017;77:7083-93.

47 Simon S, Labarriere N. Pd-1 expression on tumor-specific T cells: friend or foe for immunotherapy? Oncoimmunology 2017;7:e1364828.

48 Qin L, Zhao R, Chen D, et al. Chimeric antigen receptor T cells targeting PD-L1 suppress tumor growth. Biomark Res 2020;8:19.

49 Yang $\mathrm{C}-\mathrm{Y}$, Fan $\mathrm{MH}$, Miao $\mathrm{CH}$, et al. Engineering chimeric antigen receptor $\mathrm{T}$ cells against immune checkpoint inhibitors PD-1/ PD-L1 for treating pancreatic cancer. Mol Ther Oncolytics 2020;17:571-85

50 Shiroishi M, Kuroki K, Rasubala L, et al. Structural basis for recognition of the nonclassical MHC molecule HLA-G by the leukocyte Ig-like receptor B2 (LILRB2/LIR2/ILT4/CD85d). Proc Natl Acad Sci U S A 2006;103:16412-7.

51 Juch $\mathrm{H}$, Blaschitz A, Daxböck C, et al. A novel sandwich ELISA for alpha1 domain based detection of soluble HLA-G heavy chains. J Immunol Methods 2005;307:96-106.

52 Morales PJ, Pace JL, Platt JS, et al. Synthesis of beta(2)microglobulin-free, disulphide-linked HLA-G5 homodimers in human placental villous cytotrophoblast cells. Immunology 2007;122:179-88.

53 Kuroki K, Matsubara H, Kanda R, et al. Structural and functional basis for LILRB immune checkpoint receptor recognition of HLA-G isoforms. J Immunol 2019;203:3386-94.

54 Golubovskaya V, Wu L. Different subsets of T cells, memory, effector functions, and CAR-T immunotherapy. Cancers 2016;8:36.

55 Rossi J, Paczkowski P, Shen Y-W, et al. Preinfusion polyfunctional anti-CD19 chimeric antigen receptor T cells are associated with clinical outcomes in NHL. Blood 2018;132:804-14

56 Colonna M, Navarro F, Bellón T, et al. A common inhibitory receptor for major histocompatibility complex class I molecules on human lymphoid and myelomonocytic cells. J Exp Med 1997;186:1809-18.

57 Dumont C, Jacquier A, Verine J, et al. CD8 ${ }^{+} \mathrm{PD}^{-1} 1^{-1} \mathrm{ILT}^{+} \mathrm{T}$ Cells Are an Intratumoral Cytotoxic Population Selectively Inhibited by the Immune-Checkpoint HLA`G. Cancer Immunol Res 2019;7:1619-32.

58 Shiroishi M, Tsumoto K, Amano K, et al. Human inhibitory receptors lg-like transcript 2 (ILT2) and ILT4 compete with CD8 for MHC class I binding and bind preferentially to HLA-G. Proc Natl Acad Sci U S A 2003;100:8856-61.

59 Chu W, Fant ME, Geraghty DE, et al. Soluble HLA-G in human placentas: synthesis in trophoblasts and interferon-gammaactivated macrophages but not placental fibroblasts. Hum Immunol 1998;59:435-42.

60 Park GM, Lee S, Park B, et al. Soluble HLA-G generated by proteolytic shedding inhibits NK-mediated cell lysis. Biochem Biophys Res Commun 2004;313:606-11.

61 Köstlin N, Ostermeir A-L, Spring B, et al. HLA-G promotes myeloid derived suppressor cell accumulation and suppressive activity during human pregnancy through engagement of the receptor ILT4. Eur J Immunol 2017;47:374-84.

62 Castellaneta A, Mazariegos GV, Nayyar N, et al. HLA-G level on monocytoid dendritic cells correlates with regulatory T-cell FOXP3 expression in liver transplant tolerance. Transplantation 2011;91:1132-40.

63 Pankratz S, Bittner S, Herrmann AM, et al. Human CD4+ HLA-G+ regulatory $T$ cells are potent suppressors of graft-versus-host disease in vivo. Faseb J 2014;28:3435-45.

64 Gregori S, Tomasoni D, Pacciani V, et al. Differentiation of type 1 T regulatory cells $(\operatorname{Tr} 1)$ by tolerogenic $\mathrm{DC}-10$ requires the IL-10dependent ILT4/HLA-G pathway. Blood 2010;116:935-44.

65 Onno M, Le Friec G, Pangault C, et al. Modulation of HLA-G antigens expression in myelomonocytic cells. Hum Immunol 2000;61:1086-94.

66 Marchesi M, Andersson E, Villabona L, et al. HLA-dependent tumour development: a role for tumour associate macrophages? J Trans/ Med 2013;11:247.

67 Pangault C, Le Friec G, Caulet-Maugendre S, et al. Lung macrophages and dendritic cells express HLA-G molecules in pulmonary diseases. Hum Immunol 2002;63:83-90.

68 LeMaoult J, Krawice-Radanne I, Dausset J, et al. HLA-G1-expressing antigen-presenting cells induce immunosuppressive CD4+ T cells. Proc Natl Acad Sci U S A 2004;101:7064-9.

69 Naji A, Le Rond S, Durrbach A, et al. CD3+CD4low and CD3+CD8low are induced by HLA-G: novel human peripheral blood suppressor T-cell subsets involved in transplant acceptance. Blood 2007:110:3936-48. 
70 Teobald I, Dunnion DJ, Whitbread M, et al. Phenotypic and functional differentiation of KG-1 into dendritic-like cells. Immunobiology 2008;213:75-86.

71 Kailayangiri S, Altvater B, Meltzer J, et al. The ganglioside antigen $\mathrm{G}(\mathrm{D} 2)$ is surface-expressed in Ewing sarcoma and allows for MHCindependent immune targeting. Br J Cancer 2012;106:1123-33.

72 Kailayangiri S, Altvater B, Spurny C, et al. Targeting Ewing sarcoma with activated and GD2-specific chimeric antigen receptor- engineered human NK cells induces upregulation of immuneinhibitory HLA-G. Oncoimmunology 2017;6:e1250050.

73 Spurny C, Kailayangiri S, Altvater B, et al. T cell infiltration into Ewing sarcomas is associated with local expression of immune-inhibitory HLA-G. Oncotarget 2018;9:6536-49.

74 Wiendl $\mathrm{H}$, Mitsdoerffer M, Hofmeister V, et al. A functional role of HLA-G expression in human gliomas: an alternative strategy of immune escape. J Immunol 2002;168:4772-80. 